\title{
Pollution, Public Health Care, and Life Expectancy When Inequality Matters
}

Andreas Schaefer (schaefer@wifa.uni-leipzig.de)

Alexia Prskawetz (afp@econ.tuwien.ac.at)

\section{Approved by}

Wolfgang Lutz (lutz@iiasa.ac.at)

Leader, World Population Program

October 16, 2013

Interim Reports on work of the International Institute for Applied Systems Analysis receive only limited review. Views or opinions expressed herein do not necessarily represent those of the Institute, its National Member Organizations, or other organizations supporting the work. 


\section{Contents}

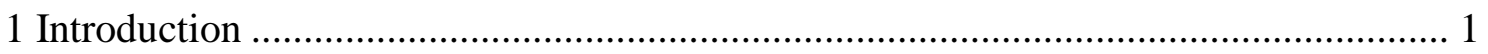

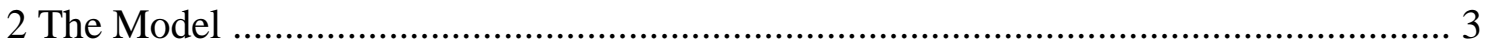

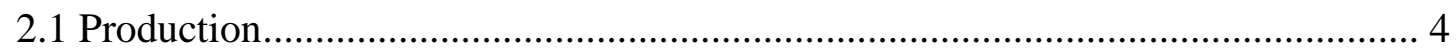

2.2 Demographics and Households’ Decisions .......................................................... 4

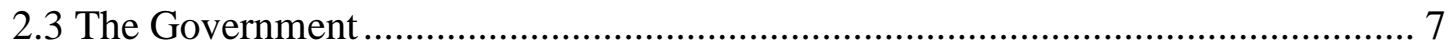

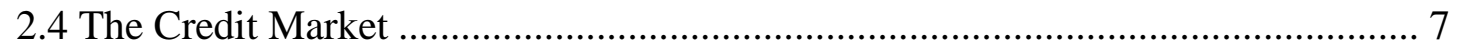

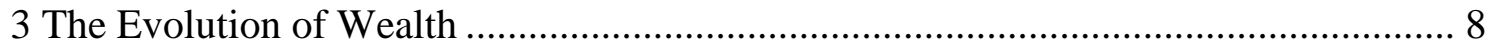

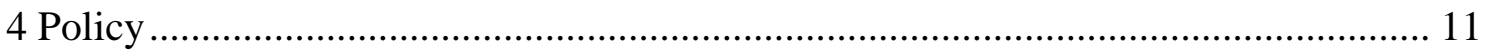

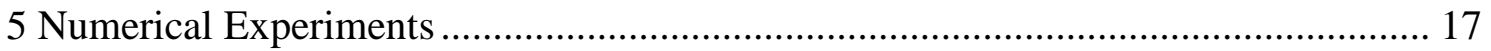

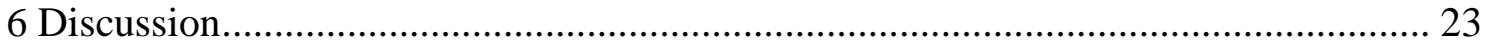

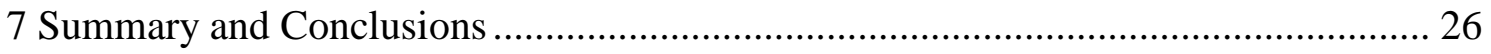

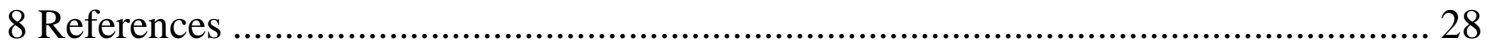

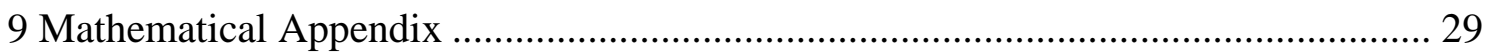




\section{Abstract}

We analyze the link between economic inequality in terms of wealth, life expectancy, health care and pollution. The distribution of wealth is decisive for the number of households investing in human capital. Moreover, the willingness to invest in human capital depends on agents' life expectancy which determines the length of the amortization period of human capital investments. Life expectancy is positively affected by public health care expenditures but adversely affected by the pollution stock generated by aggregate production. Our model accounts for an endogenous take-off in terms of human capital investments. Higher initial inequality delays the take-off because a given set of policies (abatement measures and public health care) is less effective in improving agents' survival probabilities. We compare a change in taxes to a change in expenditure shares on health and abatement given different amounts of (initial) inequality. The advantage of the latter as compared to the former is the achieved increase in the tax base which induces more expenditures on health care and abatement measures, such that an even higher economic activity is compatible with a similar level of long-run pollution. 


\section{Acknowledgments}

We would like to thank Thomas Steger, Timo Trimborn, seminar participants at the University of Leipzig, and an anonymous referee for valuable comments and constructive suggestions. The usual disclaimer applies. 


\section{About the Authors}

Andreas Schaefer is an assistant professor at the Institute for Theoretical Economics at the University of Leipzig.

Alexia Fürnkranz-Prskawetz is a professor at the Institute for Mathematical Methods in Economics at the Vienna University of Technology, deputy director at the Vienna Institute of Demography at the Austrian Academy of Sciences, director of research training at the Wittgenstein Centre for Demography and Global Human Capital (IIASA, VID/ÖAW, WU) and a research scholar with the World Population Program at IIASA. 


\title{
Pollution, Public Health Care, and Life Expectancy when Inequality Matters
}

\author{
Andreas Schaefer (schaefer@wifa.uni-leipzig.de) \\ Alexia Prskawetz (afp@econ.tuwien.ac.at)
}

\section{Introduction}

Beginning with the work of John and Pecchenio (1994) and Pecchenino et al. (1995) several authors have argued that one of the difficulties in the interaction of the environment and economic activity is the different life span of both systems. While the lifetime of the environment is infinite, the lifetime of economic agents is finite. Hence, the incentive to invest into the environment might be limited by the lifetime of the individuals. Recently a paper by Mariani et al. (2010) has extended this literature considering the two way interaction between pollution and life expectancy, i.e. it is assumed that life expectancy and environmental quality are jointly determined. In an extension to the model by Mariani et al. (2010), Raffin and Seegmuller (2012) studied the path of pollution and economic growth when households' longevity is endogenously determined not only by environmental quality but also by health policy. While economic growth may induce negative externalities on the environment, it may also be the engine of growth for investment into health and thereby enhance life expectancy. As argued in Raffin and Seegmuller (2012) the tax base will be positively associated with higher economic growth and hence more resources will be available to finance investments such as health expenditures and abatement measures. These models allow for multiple steady states, with a low level trap of high pollution and low life expectancy and a high level equilibrium with low pollution and high life expectancy. None of these models has so far considered the role of inequality in the process of economic growth. However, the initial distribution of wealth in a society may limit the possibilities for economic growth and the effectiveness of economic policy in terms of public health care and abatement measures.

In this paper, we analyze the link between economic inequality in terms of wealth, life expectancy, health care and pollution based on the work by Galor and Zeira (1993). In our framework, life expectancy is positively affected by public health care expenditures but adversely affected by the pollution stock generated by aggregate production. Life expectancy plays a key role in our model since it determines the level of human capital investment and therefore aggregate output. If households expect to live longer, they are more inclined to invest in human capital as the returns to human capital will accrue over a longer period and borrowers' credit costs shrink. We assume that the government levies taxes on households' income (where 
we distinguish between skilled and unskilled households) and uses taxes to finance health care and abatement measures. As earlier stages of economic development are characterized by low life expectancy, human capital investments are zero. However, tax financed health care and abatement measures may improve life expectancy such that agents start to invest in skills once the level of the life expectancy has passed a certain threshold. Therefore our framework takes account for an endogenous take off in terms of human capital investment. Higher initial inequality delays the take-off because a given set of policies reflected by income taxes and expenditure shares on public health care and abatement measures is less effective.

Moreover, we compare a change in taxes to a change in expenditure shares on health and abatement given different amounts of (initial) inequality. Our results show that an increase in the tax rate (hence the government budget) benefits skilled and unskilled agents in terms of wealth as long as the marginal cost of taxes in terms of foregone lifetime earnings are smaller than the marginal increase in lifetime netearnings generated through the improvement in life expectancies. However, since the marginal benefit of an increase in tax revenues for the skilled group exceeds the corresponding level of the marginal benefit of the unskilled population group, economic policy increases long-run inequality in terms of wealth. An increase in health expenditures compared to investments in abatement always raises the wealth of skilled and unskilled, but again the gain is greater for skilled workers. Moreover, we find that an increase in the expenditure share on public health care increases the tax base which induces more expenditures on health care and abatement measures, such that an even higher economic activity is compatible with a similar level of longrun pollution as compared to the levels resulting from an increase in the income tax.

The initially adverse impact of economic development on individuals' health is mirrored in the evolution of life expectancy at birth as shown in Figure 1. Average life expectancy at birth stagnated during the second phase of the industrial revolution and started to increase only in the last four decades of the 19th century. In cities, life expectancies at birth started even to decline and reached a level passed in the 15th century already, although per capita output was already growing. It is well documented that the gap in mortality rates between cities and rural areas can be explained by environmental degradation and pollution. In this line of argumentation the significance of water as an industrial raw material has been documented by Hassan (1985): fresh water was used for commercial purposes while the new entrepreneurial class saw no point in spending money for sanitation and sewage treatment plants. In addition, Hainse (2004) and Komlos (1998) provide evidence for the adverse impacts of economic development during the Industrial Revolution, in the sense that physical height of soldiers declined during the 19th century in the U.S. as well as England and the Netherlands indicating an increase in morbidity over the same period of time. Adverse effects of economic growth on the environment in earlier stages of economic development are even today of greatest concern, for example the combined health and non-health cost of outdoor air and water pollution for China's economy comes to around 5.8\% of the GDP per year (World Bank, 2007). Moreover, as regards later stages of economic development, Chay and Greenstone (2003) provide evidence for the impact of air pollution on infant mortality in the 


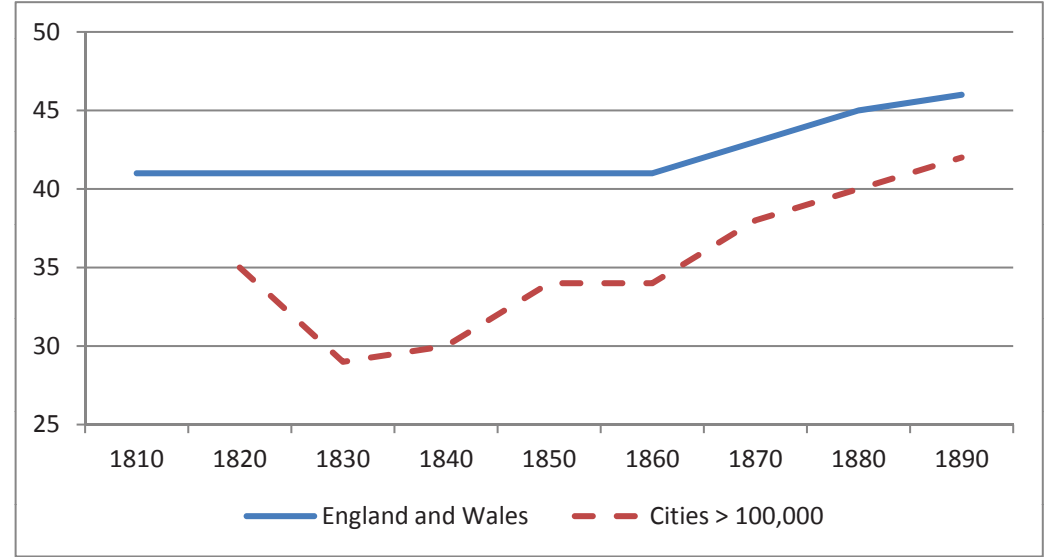

Figure 1: Expectation of life at birth (London excluded) (Szreter, 1997).

U.S. during the recession period 1981-82 and conclude that a 1-percent reduction in total suspended particulates results in a 0.35 -percent decline in infant mortality at the county level.

The remainder of the paper is organized as follows: in Section 2, we introduce the model. Section 3 explores the evolution of wealth and Section 4 discusses the set of economic policies in terms of income taxes and expenditures shares on public health care and abatement measures. In order to capture the entire evolution of the economy towards its steady state and in order to illustrate our analytical findings, we perform numerical experiments in Section 5. In Section 6, we provide a critical discussion of our results and, finally, Section 7 concludes.

\section{The Model}

Households live for two periods and decide in their first period whether or not to invest in skills. The amount of inherited wealth by the parental household determines whether agents acquire skills since the human capital investment is subject to indivisibilities and capital market imperfections in the sense that borrowers' interest rate exceeds lenders' opportunity costs. Moreover, the willingness to invest in human capital depends on agents' life expectancy as it triggers the amortization period of human capital investments. The long-run performance of the economy depends on the initial distribution of wealth which determines the number of agents investing in skills. 


\subsection{Production}

Consider a small open economy which produces a homogeneous good $Y_{t}$ in two sectors, an unskilled and a skilled sector denoted by superscripts $u, s$ in the following. Output of the unskilled sector, $Y_{t}^{u}$, is subject to a linear production function employing unskilled labor, $L_{t}^{u}$, only

$$
Y_{t}^{u}=a L_{t}^{u}, \quad a>0
$$

with $a$ denoting a positive scaling factor. The high skilled sector produces $Y_{t}^{s}$ subject to a neoclassical production function of Cobb-Douglas type and employs skilled labor, $L_{t}^{s}$, as well as physical capital, $K_{t}$, such that

$$
Y_{t}^{s}=b\left(K_{t}\right)^{\gamma}\left(L_{t}^{s}\right)^{1-\gamma}, \quad b>0, \gamma \in(0,1)
$$

with $b$ denoting a positive scaling factor and $\gamma$ representing the output elasticity of capital. Aggregate output is given by

$$
Y_{t}=Y_{t}^{s}+Y_{t}^{u}
$$

The small open economy assumption implies an exogenous interest rate that equals the international interest rate $\bar{r}$. Markets are assumed to be perfectly competitive. Given $\bar{r}$ and profit maximizing behavior of firms, the capital intensity, $k_{t}$, is determined by:

$$
\bar{r}=\gamma b k_{t}^{\gamma-1}-\delta
$$

with $k_{t}=K_{t} / L_{t}^{s}$, and $0 \leq \delta \leq 1$ representing the rate of depreciation of physical capital. In addition the wage rates for skilled and unskilled labor are given as

$$
\begin{aligned}
w_{t}^{s} & =(1-\gamma) b k_{t}^{\gamma}, \\
w_{t}^{u} & =a .
\end{aligned}
$$

Hence, the small-open economy assumption switches off any dynamics with respect to $k$ and factor prices, such that $k, w^{s}$ and $w^{u}$ are constant for all $t$, since

$$
k_{t}=\left(\frac{\gamma b}{\bar{r}+\delta}\right)^{\frac{1}{1-\gamma}} \text {. }
$$

Thus in period $t$, the level of output in the skilled sector depends only on the amount of skilled labor and exogenously fixed parameters:

$$
Y_{t}^{s}=b\left(k_{t} L_{t}^{s}\right)^{\gamma}\left(L_{t}^{s}\right)^{1-\gamma}=b^{\frac{1}{1-\gamma}}\left(\frac{\gamma}{\bar{r}+\delta}\right)^{\frac{\gamma}{1-\gamma}} L_{t}^{s} .
$$

\subsection{Demographics and Households' Decisions}

An individual born in $t-1$ expects to live for $1+\phi_{t}$ periods with $0 \leq \phi_{t} \leq 1$ representing the probability to reach the end of period $t$ (see also Figure 2). Hence the terms life expectancy and survival probability can be used interchangeably. The probability to reach the end of the second period of life is determined by the level of public health expenditures, $H_{t}$, and the exposure to pollutants, $P_{t}$, i.e. $\phi_{t}=\phi\left(H_{t}, P_{t}\right)$. 


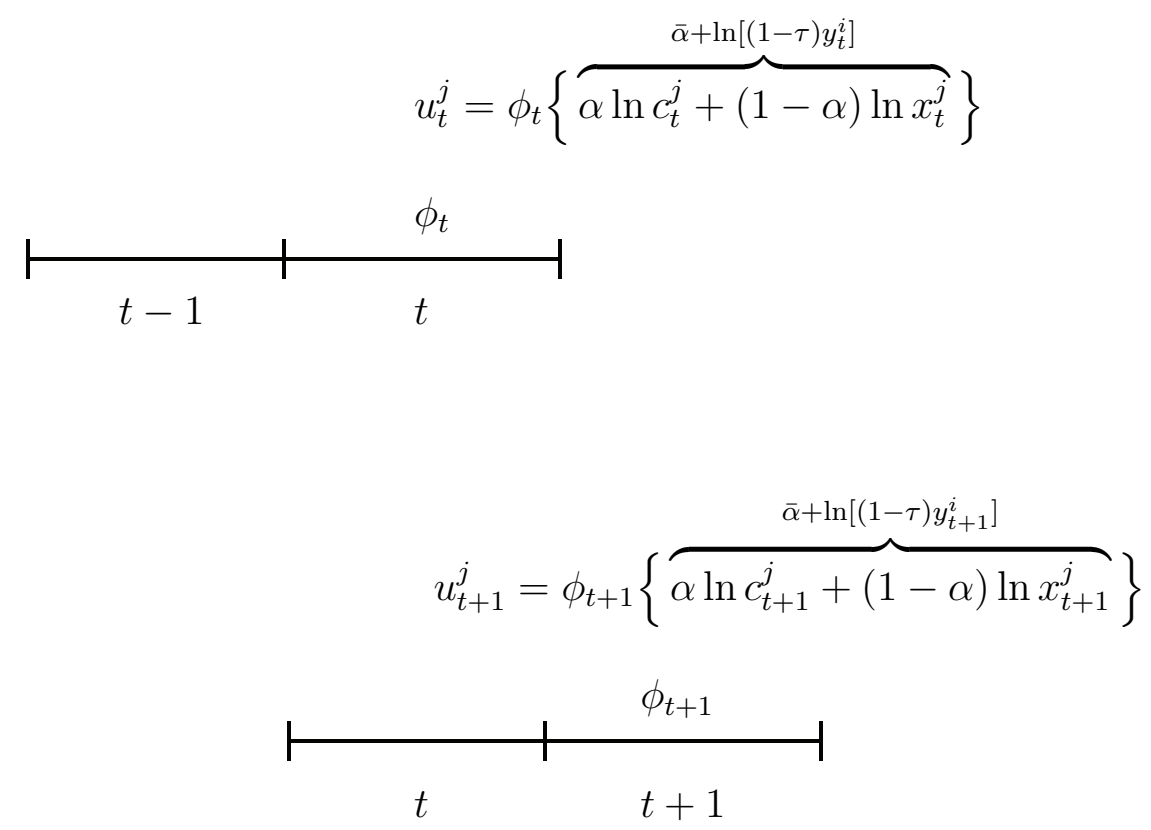

Figure 2: Demographics

Definition 1 Life expectancy $0 \leq \phi_{t} \leq 1$ is a non-decreasing function in public health care expenditures, $H_{t}$, and a non-increasing function in the pollution stock $P_{t}$, such that

$$
\begin{aligned}
& \frac{\partial \phi\left(H_{t}, P_{t}\right)}{\partial H_{t}} \geq 0, \\
& \frac{\partial \phi\left(H_{t}, P_{t}\right)}{\partial P_{t}} \leq 0 .
\end{aligned}
$$

Moreover, the cross-derivative is non-positive, i.e.

$$
\frac{\partial^{2} \phi\left(H_{t}, P_{t}\right)}{\partial H_{t} \partial P_{t}} \leq 0
$$

A non-positive cross-derivative of the life expectancy with respect to $H$ and $P$ means that an increase in pollution may reduce the effectiveness of public health expenditures on $\phi$.

At this point it is worth to notice that public health expenditures improve the life expectancy of those generations which are taxed while an improvement of environmental quality reflected by a decline of the pollution stock in the subsequent period, $P_{t+1}$, benefits only those generations which are at life from $t+1$ onwards. Moreover, in Section 2.3, we will see that public health expenditures depend on aggregate 
tax revenues, i.e. aggregate income. Since we abstract from population growth an increase in aggregate income corresponds to an increase in per capita income and thus to an improvement in health expenditures and life expectancy. Thus our theory is compatible to the well-known Preston-curve suggesting a positive association between per capita income and life expectancy.

Note that we only consider public expenditures on health and ignore private health expenditures. Our approach is similar to Aisa and Pueyo (2006). Different to Aisa and Pueyo we assume that the level of health expenditures and not the share of health expenditures in total GDP positively affects life expectancy. ${ }^{1}$ By only focusing on public health care we aim to emphasize the role of the allocation of public expenditures between health care and pollution abatement on economic growth (see also Agenor and Neanidis 2011). On one hand health expenditures reduce income through taxes thereby also reducing spending on pollution abatement, on the other hand higher taxes induce a higher life expectancy and thereby foster human capital accumulation and economic growth.

Agents, $j$, work either as unskilled workers, $j=u$, in both periods or invest in their first period of life in human capital and become a skilled worker, $j=s$, in their second period of life. Fertility is exogenous in the sense that each household has exactly one descendant which replaces him after she dies. Agents born in $t-1$ derive utility out of consumption, $c_{t}^{j}$, and out of bequests to their offspring, $x_{t}^{j}$, in their second period of life . Lifetime utility in $t$ of an agent $j$ born in period $t-1$ is specified as

$$
u_{t}^{j}=E\left[\bar{u}_{t}^{j}\right]=\phi_{t}^{j} \bar{u}_{t}^{j}
$$

with $\phi_{t}^{j}=\phi_{t} \forall j$ and $\bar{u}_{t}^{j}=\alpha \ln c_{t}^{j}+(1-\alpha) \ln x_{t}^{j}$. Hence, we assume the same life expectancy for skilled and unskilled people.

An agent $j$ born in period $t-1$ maximizes lifetime utility (12) subject to lifetime earnings net of taxes, $\tau \in(0,1)$, resulting in

$$
\begin{aligned}
c_{t}^{j} & =\alpha(1-\tau) y_{t}^{j}, \\
x_{t}^{j} & =(1-\alpha)(1-\tau) y_{t}^{j},
\end{aligned}
$$

with $y_{t}^{j}$ denoting agents' second period's income depending on life expectancy $\phi_{t}$. Before we specify life time earnings further below, we obtain the indirect utility function from (12)-(14) as

$$
\bar{u}_{t}^{j}=\bar{\alpha}+\ln \left[(1-\tau) y_{t}^{j}\right]
$$

with $\bar{\alpha}=\alpha \ln \alpha+(1-\alpha) \ln [1-\alpha]$.

\footnotetext{
${ }^{1}$ But remember that pollution adversely affects agents' life expectancy in our framework. Moreover, we will assume further below a logistic functional form of $\phi\left(H_{t}, P_{t}\right)$. Thus our model is not more optimistic with respect to the effectiveness of public health expenditures on improvements of $\phi$ compared to existing literature.
} 


\subsection{The Government}

The government raises income taxes $\tau \in(0,1)$ in order to finance public health expenditures $H_{t}$ and abatement measures $A_{t}$. In period $t$ the government taxes unskilled households working in their first period of life, $L_{t}^{u}$, and skilled and unskilled households born in $t-1$ that survived to period $t$, i.e. $\phi_{t}\left(L_{t-1}^{u}+L_{t-1}^{s}\right)$. Hence tax revenues in period $t$ are

$$
G_{t}=\tau\left(\phi_{t}\left(y_{t}^{s} L_{t-1}^{s}+y_{t}^{u} L_{t-1}^{u}\right)+w^{u} L_{t}^{u}\right) .
$$

Abstracting from intertemporal debts and assuming constant expenditure shares for public health, $\nu$, and abatement measures, $1-\nu$, a balanced budget in each period requires

$$
\begin{aligned}
H_{t} & =\nu G_{t}, \\
A_{t} & =(1-\nu) G_{t}, \quad \nu \in(0,1) .
\end{aligned}
$$

In $t+1$, the stock of pollutants, $P_{t+1}$, increases by current emissions, $E_{t}$, generated by the production process. We assume for simplicity $E_{t}=E\left(Y_{t}\right)=\varepsilon_{0} Y_{t}$. On the other hand, the impact of emissions on the pollution stock can be reduced through tax financed abatement measures, $A_{t}$. Moreover, the environment regenerates at rate $0<\eta<1$, such that the pollution stock evolves over time according to

$$
P_{t+1}=(1-\eta) P_{t}+\varepsilon_{0} Y_{t}-\varepsilon_{1} A_{t}, \quad 0<\varepsilon_{1}<\varepsilon_{0}, \eta \in(0,1),
$$

with $\varepsilon_{0}$ denoting the impact of one unit of output on the pollution stock and $\varepsilon_{1}$ reflecting the productivity of abatement measures.

\subsection{The Credit Market}

The credit market is subject to imperfections as in Galor and Zeira (1993), in the sense that borrowers' interest rate, $i_{t}$, exceeds the world market interest rate, $\bar{r}$. In contrast to Galor and Zeira (1993), $i_{t}$ depends inversely on agents' life expectancy, $\phi_{t}$. Moreover, as $\phi_{t}=\phi\left(H_{t}, P_{t}\right)$, borrowers' credit costs are not time invariant and affected by public health expenditures and abatement measures triggering the wedge between $i_{t}$ and $\bar{r}$. Thus economic policy affects the incentive to invest in skills (by determining life expectancy), but the effectiveness of economic policy will depend on the amount of economic inequality. Before we come back to this issue further below, we elaborate more on the mechanisms on the credit market.

Human capital investments are (see Galor and Zeira, 1993) subject to indivisibilities, in the sense that it requires an amount $h>0$ to become a skilled worker. Workers born in $t-1$ with inherited wealth $x_{t-1}^{j}<h$ can borrow $h-x_{t-1}^{j}$ at the capital market, but since human capital investments are unobservable and the transition to the end of the second period of life is uncertain, moral hazard and mortality risks induce a wedge between the equilibrium interest rate $\bar{r}$ and the interest rate $i_{t}$ at which lenders are willing to lend money to borrowers. Hence, credits are subject to monitoring costs $z$, such that the zero profit condition is given by

$$
\left(1+i_{t}\right) \phi_{t}\left(h-x_{t-1}^{j}\right)=z+(1+\bar{r})\left(h-x_{t-1}^{j}\right) .
$$


The left hand side denotes the lender's credit costs, i.e. the interest rate that the lender faces times the probability to survive to the end of the next period and times the amount of investment to be borrowed. The right hand side indicates the costs that accrue to the borrower. These are the monitoring costs, $z$, plus the value of the borrowed investment if it would be invested at the international interest rate.

As lenders can still evade repayment by spending $\beta z$ with $\beta>1$, borrowers set monitoring effort, $z$, such that lenders are indifferent between repayment and evasion

$$
\left(1+i_{t}\right) \phi_{t}\left(h-x_{t-1}^{j}\right)=\beta z .
$$

From the last two equations we obtain $i_{t}$

$$
\begin{aligned}
\left(1+i_{t}\right) \phi_{t}\left(h-x_{t-1}^{j}\right) & =\frac{\left(1+i_{t}\right) \phi_{t}\left(h-x_{t-1}^{j}\right)}{\beta}+(1+\bar{r})\left(h-x_{t-1}^{j}\right) \\
\Rightarrow i_{t} & =\frac{\beta}{(\beta-1)} \frac{(1+\bar{r})}{\phi_{t}}-1 .
\end{aligned}
$$

The following proposition summarizes the association between borrower's and lender's interest rates as well as life expectancy.

Proposition 1 Since $\beta>1$ it follows that $i_{t}>\bar{r}^{2}{ }^{2}$ Moreover, the interest rate for credits, $i_{t}$, is inversely related to life expectancy, i.e. $\frac{\partial i_{t}}{\partial \phi_{t}}<0$, such that higher health risks increase lenders' credit costs.

\section{The Evolution of Wealth}

Lifetime utility (15) of agents born in $t$ depends positively on lifetime earnings $y_{t+1}^{j}$ which in turn depends on human capital investment. Whether or not to invest in human capital depends on the level of inherited bequests, i.e. $x_{t}^{j} \gtreqless h$, and life expectancy $\phi_{t+1}$, with $h$ representing an exogenous fixed cost of human capital investment. Households with $x_{t}^{j} \geq h$ invest in human capital, if lifetime utility of becoming a skilled worker is at least as high as lifetime utility from remaining unskilled, i.e. $u_{t+1}^{s} \geq u_{t+1}^{u}$ which implies in light of (15) that $y_{t+1}^{s} \geq y_{t+1}^{u}$, such that

$$
\underbrace{\phi_{t+1} w^{s}+\left(x_{t}^{j}-h\right)(1+\bar{r})}_{y_{t+1}^{s}} \geq \underbrace{\phi_{t+1} w^{u}+\left((1-\tau) w^{u}+x_{t}^{j}\right)(1+\bar{r})}_{y_{t+1}^{u}} \cdot{ }^{3}
$$

\footnotetext{
${ }^{2} i_{t}>\bar{r}$ implies $\frac{(1+\bar{r}) \beta}{\phi_{t}(\beta-1)}>1+\bar{r}$ and therefore $\frac{\beta}{(\beta-1)}>\phi_{t}$ which is valid as long as $\beta>1$ since $0<\phi_{t} \leq 1$.
} 
In contrast, households with $x_{t}^{j}<h$ wish to invest in human capital, if $u_{t+1}^{u, s} \geq u_{t+1}^{u} \cdot{ }^{4}$ These households borrow $h-x_{t}^{j}$ at an interest rate $i_{t+1}$ from the capital market, such that

$$
(1-\tau) y_{t+1}^{u, s}=(1-\tau)\left(w^{s} \phi_{t+1}+\left(x_{t}^{j}-h\right)\left(1+i_{t+1}\right)\right), \quad \text { with } x_{t}^{j}<h .
$$

The requirement of $u_{t+1}^{u, s} \geq u_{t+1}^{u}$ implies again in light of (15) that the last expression holds with equality, if

$$
y_{t+1}^{u, s}=y_{t+1}^{u}
$$

Condition (26) determines the minimum level of inherited wealth necessary to become a skilled worker, $x_{t}^{j}=x_{t}^{\text {crit }}$, conditional on the survival probability $\phi_{t+1}$ :

$$
x_{t}^{c r i t}=\frac{1}{i_{t+1}-\bar{r}}\left[(1-\tau) w^{u}(1+\bar{r})+h\left(1+i_{t+1}\right)-\phi_{t+1}\left(w^{s}-w^{u}\right)\right] \text {. }
$$

Since $x_{t+1}^{j}=(1-\alpha)(1-\tau) y_{t+1}^{j}$ and given that $y_{t+1}^{s} \geq y_{t+1}^{u}$, wealth of agents born in $t$ given life expectancy, $\phi_{t+1}$, evolves according to:

(1) Agents born in unskilled households with $x_{t}^{u}<x_{t}^{\text {crit }}$ remain unskilled

$$
\begin{aligned}
x_{t+1}^{u}= & (1-\alpha)(1-\tau) y_{t+1}^{u} \\
= & (1-\alpha)(1-\tau)\left[\left(x_{t}^{u}+(1-\tau) w^{u}\right)(1+\bar{r})+w^{u} \phi_{t+1}\right],
\end{aligned}
$$

(2) Agents born in skilled households with $x_{t}^{s} \geq h$ invest in skills

$$
x_{t+1}^{s}=(1-\alpha)(1-\tau) y_{t+1}^{s}=(1-\alpha)(1-\tau)\left[w^{s} \phi_{t+1}+\left(x_{t}^{s}-h\right)(1+\bar{r})\right],
$$

(3) Agents born in unskilled households with $h>x_{t}^{u} \geq x_{t}^{\text {crit }}$ invest in skills

$$
x_{t+1}^{u, s}=(1-\alpha)(1-\tau) y_{t+1}^{u, s}=(1-\alpha)(1-\tau)\left[w^{s} \phi_{t+1}+\left(x_{t}^{u}-h\right)\left(1+i_{t+1}\right)\right] .
$$

The system (28)-(30) can be presented graphically in the $\left(x_{t+1}, x_{t}\right)$-plane for a given stock of pollution and public health expenditures, i.e. a given life expectancy $\phi_{t+1}$. Thus, the loci depicted in Figure 3 are conditional on the state of $\phi_{t+1}$. conditional on the state of $\phi_{t+1}$. This is the reason why we refer to conditional loci and steady states. The positions and the slope of these conditional loci and steady states are important as they trigger the dynamics of the economy to their long-run values and the composition of the population in terms of skilled and unskilled agents. We will describe the behavior of the conditional steady states and $x_{t}^{\text {crit }}$ in detail further

\footnotetext{
${ }^{3}$ The left-hand side of the last expression captures the lifetime income of a skilled household in her second period of life, i.e. labor income, $w^{s}$, multiplied by the corresponding level of life expectancy, $\phi_{t+1}$ plus wealth net human capital investment times accrued interests, $\left(x_{t}^{j}-h\right)(1+r)$. The right-hand side captures lifetime income of an unskilled household that does not invest in human capital, i.e. labor income, $w^{u}$, multiplied by $\phi_{t+1}$, plus the sum out of first-period labor income net of taxes, $(1-\tau) w^{u}$, and wealth, $x_{t}^{j}$, times accrued interests.

${ }^{4}$ The superscript $u, s$ denotes agents that are born in unskilled households and decide to invest in skills.
} 


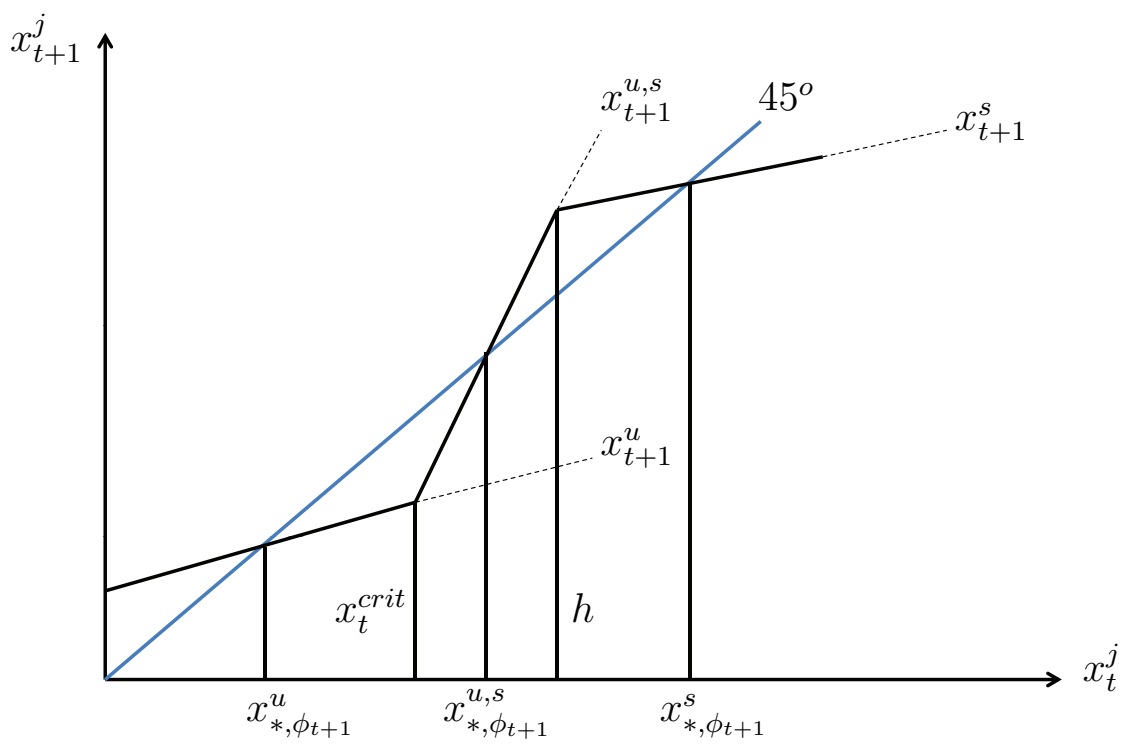

Figure 3: Evolution of wealth conditional on life expectancies $\phi_{t+1}$ and taxes $\tau$

below (see also Figure 4). Noting that $i_{t+1}$ is a function of $\phi_{t+1}$, the conditional stationary solutions read as follows

$$
\begin{aligned}
x_{*, \phi_{t+1}}^{s} & =\frac{(1-\alpha)(1-\tau)\left(w^{s} \phi_{t+1}-h(1+\bar{r})\right)}{1-(1-\alpha)(1-\tau)(1+\bar{r})} \\
x_{*, \phi_{t+1}}^{u} & =\frac{(1-\alpha)(1-\tau) w^{u}\left((1+\bar{r})(1-\tau)+\phi_{t+1}\right)}{1-(1-\alpha)(1-\tau)(1+\bar{r})} \\
x_{*, \phi_{t+1}}^{u, s} & =\frac{(1-\alpha)(1-\tau)\left(h\left(1+i_{t+1}\right)-w^{s} \phi_{t+1}\right)}{(1-\alpha)(1-\tau)\left(1+i_{t+1}\right)-1}
\end{aligned}
$$

with $1>(1-\alpha)(1-\tau)(1+\bar{r})$ and $(1-\alpha)(1-\tau)\left(1+i_{t+1}\right)>1 .^{5}$

The steady state of the economy is determined by the initial distribution of wealth, $\Gamma_{0}$, and the policy set $\Phi=\{\tau, \nu\}$. Both in combination determine the long-run distribution of wealth $\Gamma_{*}$ which in turn is determined by the distribution of the population between the two stable steady states $x_{*, \phi_{*}}^{u}$ and $x_{*, \phi_{*}}^{s}$. The following proposition describes the steady state of our economy.

Proposition 2 The steady state of the economy is characterized by a constant life

\footnotetext{
${ }^{5}$ As can be verified easily: $\phi_{t+1}>(1-\alpha)(1-\tau)(1+\bar{r})$ implies that the exterior (conditional) steady states are stable while $(1-\alpha)(1-\tau)\left(1+i_{t+1}\right)>1$ implies that the interior one is unstable.
} 
expectancy, $\phi_{t}=\phi_{*} \leq 1$, which implies a constant interest rate

$$
i_{*}=\frac{\beta(1+\bar{r})}{(\beta-1) \phi_{*}}-1
$$

a constant level of wealth for skilled and unskilled households

$$
\begin{aligned}
x_{*, \phi_{*}}^{s} & ==\frac{(1-\alpha)(1-\tau)\left(w^{s} \phi_{*}-h(1+\bar{r})\right)}{1-(1-\alpha)(1-\tau)(1+\bar{r})}, \\
x_{*, \phi_{*}}^{u}= & =\frac{(1-\alpha)(1-\tau) w^{u}\left((1+\bar{r})(1-\tau)+\phi_{*}\right)}{1-(1-\alpha)(1-\tau)(1+\bar{r})}, \\
x_{*, \phi_{*}}^{u, s}= & \frac{(1-\alpha)(1-\tau)\left(h\left(1+i_{*}\right)-w^{s} \phi_{*}\right)}{(1-\alpha)(1-\tau)\left(1+i_{*}\right)-1},
\end{aligned}
$$

with $1>(1-\alpha)(1-\tau)(1+\bar{r})$ and $(1-\alpha)(1-\tau)\left(1+i_{*}\right)>1$, and a constant distribution of households between the two exterior steady states $x_{*, \phi_{*}}^{s}$ and $x_{*, \phi_{*}}^{u}$, such that $L_{t}^{u}=L_{*}^{u} \geq 0$ and $L_{t}^{s}=L_{*}^{s} \geq 0$ with $L_{*}^{u}+L_{*}^{s}=L$. Therefore the level of aggregate production $Y_{t}=Y_{*}$ is constant as well and reads

$$
Y_{*}=Y_{*}^{u}+Y_{*}^{s}=a L_{*}^{u}+b^{\frac{1}{1-\gamma}}\left(\frac{\gamma}{\bar{r}+\delta}\right)^{\frac{\gamma}{1-\gamma}} L_{*}^{s},
$$

such that the level of Pollution, $P$, tax revenues, $G$, public health expenditures, $H$, and abatement measures, $A$, are constant as well and given by

$$
\begin{aligned}
P_{*} & =\frac{\varepsilon_{0} Y_{*}+\varepsilon_{1}(1-\nu) \tau G_{*}}{\eta}, \\
G_{*} & =\tau\left(\phi_{*}\left(y_{t}^{s} L_{*}^{s}+y_{t}^{u} L_{*}^{u}\right)+w_{t}^{u} L_{*}^{u}\right), \\
H_{*} & =\nu G_{*}, \\
A_{*} & =(1-\nu) G_{*} .
\end{aligned}
$$

\section{Policy}

In this section we analyze changes in the policy set $\Phi=\{\tau, \nu\}$. Changes in $\Phi$ alter life expectancy and therefore the skill composition of the population given the initial distribution of wealth $\Gamma_{0}$. Thus economic policy has a direct impact on the evolution of inequality and the long-run performance of an economy. Changes in $\tau$ alter life expectancies, interest rates, disposable incomes of households, and resources available for abatement measures. In contrast, a change in $\nu$ leaves disposable incomes unaffected.

Before turning to changes in $\Phi$, it will be instructive to analyze the effects of changes in life expectancies, $\phi$, on the (conditional) steady states and $x_{t}^{\text {crit }}$. We thus analyze the dynamics of the conditional steady states (i.e. the shift of the respective intercepts with the $45^{\circ}$-line in Figure 3), in response to the transition of $\phi$ towards its long-run value $\phi_{*} \leq 1$. As we will see, the increase in $\phi$ gives rise to an endogenous take off in terms of human capital investments. This take-off is essentially triggered 
by the dynamics of the conditional stable steady states, $x_{*, \phi_{t+1}}^{u}$, and $x_{*, \phi_{t+1}}^{s}$, while the dynamics of the wealth distribution and the composition of the population in terms of skilled and unskilled households is affected by $x_{t}^{c r i t}$ and $x_{*, \phi_{t+1}}^{u, s}{ }^{6}$ The analytical results are summarized in Proposition 3 and 4. The following proposition summarizes the dependence of $x_{*, \phi_{t+1}}^{u}$ and $x_{*, \phi_{t+1}}^{s}$ in response to a change in $\phi$.

Proposition 3 (Exterior steady states, changes in $\phi$ ) (i) An increase in longevity increases the (conditional) long-run levels of wealth for skilled and unskilled households, i.e. $\frac{\partial x_{*, \phi_{t+1}}^{u}}{\partial \phi_{t+1}} \geq 0$ and $\frac{\partial x_{*, \phi_{t+1}}^{s}}{\partial \phi_{t+1}} \geq 0$ for $\phi_{t+1} \in\left(0, \phi_{*}\right)$, and $\phi_{*} \leq 1$, where

$$
\begin{aligned}
\frac{\partial x_{*, \phi_{t+1}}^{u}}{\partial \phi_{t+1}} & =\frac{(1-\alpha)(1-\tau) w^{u}}{1-(1-\alpha)(1-\tau)(1+\bar{r})} \geq 0 \\
\frac{\partial x_{*, \phi_{t+1}}^{s}}{\partial \phi_{t+1}} & =\frac{(1-\alpha)(1-\tau) w^{s}}{1-(1-\alpha)(1-\tau)(1+\bar{r})} \geq 0
\end{aligned}
$$

with equality, if $\phi_{t+1}=1$. Moreover, $\frac{\partial x_{*, \phi_{t+1}}^{u}}{\partial \phi_{t+1}}<\frac{\partial x_{*, \phi_{t+1}}^{s}}{\partial \phi_{t+1}}$ since $w^{u}<w^{s}$.

(ii) As life expectancy approaches zero, the (conditional) stable steady states of both population groups reach a minimum value

$$
\begin{aligned}
& x_{*, \text { min }}^{s}=-\frac{(1-\tau)(1-\alpha)(1+\bar{r}) h}{1-(1-\alpha)(1-\tau)(1+\bar{r})}<0 \\
& x_{*, \text { min }}^{u}=\frac{(1-\tau)^{2}(1+\bar{r})(1-\alpha) w^{u}}{1-(1-\alpha)(1-\tau)(1+\bar{r})}>0 .
\end{aligned}
$$

(iii) Given that $\phi_{*}$ is such that $x_{*, \phi_{*}}^{s}>x_{*, \phi_{*}}^{u}$, it follows from (i) and (ii) that there exists a critical $\phi^{c}<\phi_{*}$ implying that $x_{*, \phi^{c}}^{s}=h$, such that agents with $x_{t}^{j} \geq h$ start to invest in skills for $\phi \geq \phi^{c} .7$

In Figure 4, we depict the conditional steady states $x_{*, \phi_{t+1}}^{u}$ and $x_{*, \phi_{t+1}}^{s}$ as linear functions of $\phi$ starting at $x_{*, \text { min }}^{u}>0$ and $x_{* \text { min }}^{s}<0$, respectively. In light of item (i), both population groups benefit from increasing life expectancies, but the marginal effect is stronger for the skilled population group as $w^{s}>w^{u}$. Moreover, life expectancy must exceed a threshold $\phi^{c}$ in order to make investments in human capital profitable, in the sense that life expectancies above $\phi^{c}$ (items (ii) and (iii)) assure that lifetime utility of a skilled agent exceeds lifetime utility of remaining unskilled given that the amount of inherited wealth $x_{t}^{j}$ is at least $h$. The threshold $\phi^{c}$ implies that the (conditional) steady state level of wealth for the skilled population group is as least as high as $h$. Since life expectancy is endogenous, our model is therefore able to generate an endogenous take-off in terms human capital investment.

\footnotetext{
${ }^{6}$ Remember that $x_{t}^{\text {crit }}$ determines the necessary amount of wealth to become a skilled worker for a given life expectancy while $x_{*, \phi_{t+1}}^{u, s}$ determines the basin of attraction of the superior steady state for a given life expectancy.

${ }^{7}$ Note that $x_{*, \tilde{\phi}}^{u}=x_{*, \tilde{\phi}}^{s}$ implies $w^{s} \tilde{\phi}-(1+\bar{r}) h=(1-\tau)(1+\bar{r}) w^{u}+\tilde{\phi} w^{u}$. This threshold however is irrelevant, since $h>x_{*}^{s}$.
} 


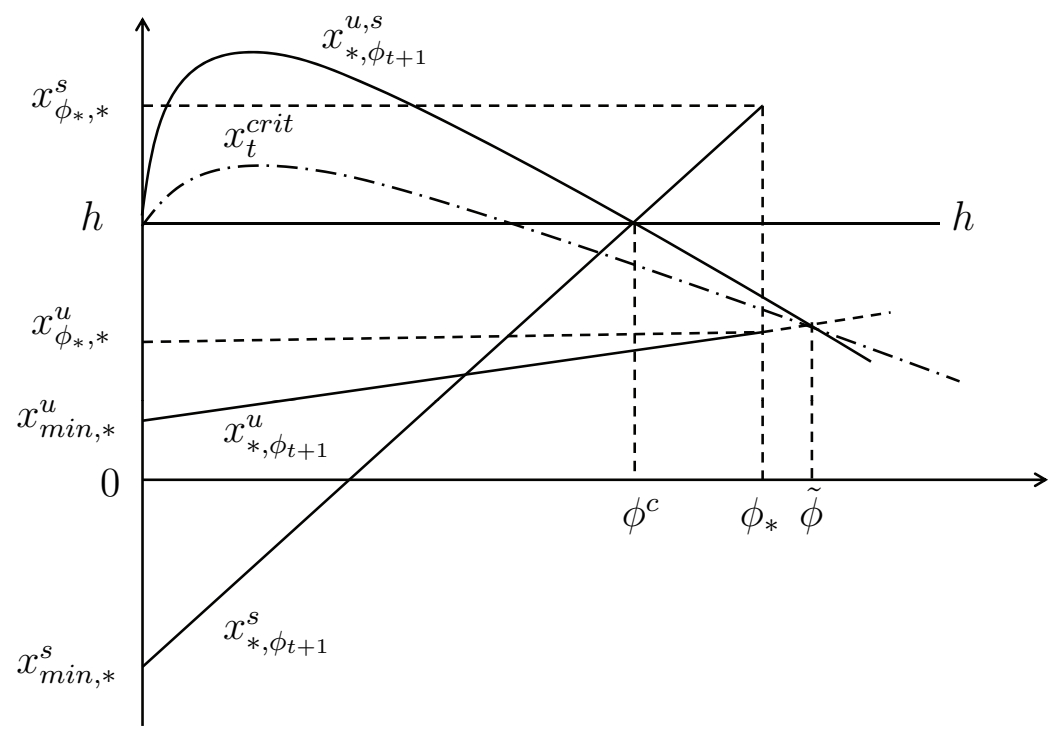

Figure 4: The (conditional) steady states and $x_{t}^{c r i t}$ as a function of life expectancy $\phi$.

The next feature of our framework is the dynamics of the wealth distribution as influenced by the evolution of life expectancies over time. For the long-run composition of the population in terms of skilled and unskilled households, the location of the minimum amount of wealth necessary to invest in skills, $x_{t}^{\text {crit }}$, and the location of the unstable interior (conditional) steady state, $x_{*, \phi_{t+1}}^{u, s}$, are crucial. More precisely, the distance between $x_{t}^{c r i t}$ and $x_{*, \phi_{t+1}}^{u, s}$ is crucial for the long run distribution of the population. Though a decline in $x_{t}^{\text {crit }}$ facilitates more unskilled households to invest in skills, it is the location of $x_{*, \phi_{t+1}}^{u, s}$ that demarcates the basin of attraction of the two exterior steady states. Hence a reduction in $x_{t}^{c r i t}$ given a distribution of wealth $\Gamma_{t}$ is beneficial for unskilled households during the transition, but not necessarily in the long-run as long as the decline in $x_{t}^{c r i t}$ is not accompanied by a decline in $x_{*, \phi_{t+1}}^{u, s}$ which assures that more unskilled dynasties transit towards the superior steady state. The following proposition shows the sensitivity of the interior (conditional) steady state and the minimum level of wealth necessary to invest in skills when life expectancy changes.

Proposition 4 (Interior steady state, $x_{*, \phi_{t+1}}^{u, s}, x_{t}^{c r i t}$, and changes in $\phi_{t+1}$ ) The minimum level of wealth, $x_{t}^{\text {crit }}$, necessary to become a skilled worker for agents with wealth $x_{t}^{j}<h$ and the interior unstable conditional steady state $x_{*, \phi_{t+1}}^{u, s}$ are hump- 
shaped in $\phi_{t+1}$, whereby it holds that $x_{*, \phi_{t+1}}^{u, s}>x_{t}^{\text {crit }}$ if $0<\phi_{t}<\tilde{\phi}$, where $\phi=\tilde{\phi}$ implies $x_{t}^{\text {crit }}=x_{*, \phi_{t+1}}^{u, s}$. Moreover, $x_{t}^{\text {crit }}$ and $x_{*, \phi_{t+1}}^{u, s}$ are declining in $\phi$ for $\phi^{c} \leq \phi_{t+1} \leq \phi_{*}$. (Proof, see Appendix)

In light of Proposition 4, see also Figure 4, it follows that an increase in life expectancy lowers the minimum level of wealth necessary to become a skilled worker, $x_{t}^{c r i t}$, and the unstable interior (conditional) steady state, $x_{*, \phi_{t+1}}^{u, s}$, in the relevant interval $\phi \in\left(\phi^{c}, \phi_{*}\right)$. Since, $x_{t}^{c r i t}=x_{*, \phi_{t+1}}^{u, s}$, if $\phi_{t}=\tilde{\phi}$, the distance between $x_{t}^{\text {crit }}$ and $x_{*, \phi_{t+1}}^{u, s}$ declines with increasing life expectancy. Thus, the improvement in life expectancy is beneficial for descendants of unskilled households that wish to invest in skills. With the induced decline of $x_{*, \phi_{t+1}}^{u, s}$ the demarcation line of the two basins of attraction shrinks as well, such that more descendants of unskilled households that invested in skills may transit towards the superior long-run equilibrium $x_{*, \phi_{*}}^{s}$ which would have converged otherwise towards the inferior equilibrium $x_{*, \phi_{*}}^{u}$. How sizable this effect is depends on the distribution of wealth, $\Gamma_{t}$, in the sense that a more equal distribution of wealth locates more unskilled households in the vicinity of $x_{*, \phi_{t+1}}^{u, s}$, such that more unskilled households investing in skills benefit from the improvement in $\phi$ and transit towards $x_{*, \phi_{*}}^{S}$. In other words, the effect of improving health conditions on the long-run performance of the economy depends on $\Gamma_{t}$. Likewise, we will see that the effectiveness of economic policy in terms of $\Phi$ depends on $\Gamma_{t}$.

We next study the reaction of the (conditional) steady states in response to a change in the policy set $\Phi=\{\tau, \nu\}$. The following proposition summarizes the sensitivity of the two exterior stable (conditional) steady states in response to change in the tax rate $\tau$ :

Proposition 5 (Effects of $\tau$ on $x_{*, \phi_{t+1}}^{s}$ and $x_{*, \phi_{t+1}}^{u}$ ) (i) The (conditional) steady state of the skilled population group increases in response to an increase in $\tau$, if

$$
(1-\tau) w^{s} \frac{\partial \phi_{t+1}}{\partial \tau}>\frac{w^{s}-h(1+\bar{r})}{1-(1-\tau)(1-\alpha)(1+\bar{r})}=\frac{x_{*, \phi_{t+1}}^{s}}{(1-\alpha)(1-\tau)}=y_{*, \phi_{t+1}}^{s} .
$$

(ii) The (conditional) steady state of the unskilled population group increases in response to an increase in $\tau$, if

$$
\begin{aligned}
& (1-\tau)\left(\frac{\partial \phi_{t+1}}{\partial \tau}-(1+\bar{r})\right) w^{u} \\
& >\frac{[(1+\bar{r})(1-\tau)+\phi] w^{u}}{1-(1-\tau)(1-\alpha)(1+\bar{r})}=\frac{x_{*, \phi_{t+1}}^{u}}{(1-\alpha)(1-\tau)}=y_{*, \phi_{t+1}}^{u}
\end{aligned}
$$

Proposition 5 states that an increase in $\tau$ benefits skilled and unskilled agents in terms of wealth as long as the marginal cost of taxes in terms of forgone lifetimes earnings (right-hand side of the equations) are smaller than the marginal increase in lifetime net-earnings generated through the improvement in life expectancy, $\frac{\partial \phi_{t+1}}{\partial \tau}>$ 
0 (left-hand side of the equations). Furthermore, the marginal benefit of the skilled population group exceeds the marginal benefit of the unskilled population group, as

$$
\frac{w^{s}}{w^{u}}>\frac{\frac{\partial \phi_{t+1}}{\partial \tau}-(1+\bar{r})}{\frac{\partial \phi_{t+1}}{\partial \tau}},
$$

since $w^{s}>w^{u}$ and $\frac{\frac{\partial \phi_{t+1}}{\partial \tau}-(1+\bar{r})}{\frac{\partial \phi_{t+1}}{\partial \tau}}<1$. Moreover, the marginal benefit of the unskilled population group may even turn negative, if $\frac{\partial \phi_{t+1}}{\partial \tau}<(1+\bar{r})$. Interestingly, economic policy increases long-run inequality in terms of wealth through its asymmetric impact on the long-run levels of wealth for skilled and the unskilled population group. However, this effect is at least partially compensated by a reduction in $x_{t}^{\text {crit }}$ and $x_{*, \phi_{t+1}}^{u, s}$ in response to an increase in taxes

Proposition 6 (Effects of $\tau$ on $x_{*, \phi_{t+1}}^{u, s}$ and $x_{t}^{c r i t}$ ) (i) The interior steady state declines in response to an increase in $\tau$, i.e. $\frac{\partial x_{*, \phi_{t+1}}^{u, s}}{\partial \tau}<0$, if

$$
\begin{aligned}
& {\left[h\left(1+i_{t+1}\right)-w^{s} \phi_{t+1}\right]+(1-\tau) \frac{\partial \phi_{t+1}}{\partial \tau}\left[w^{s}-h \frac{\partial\left(1+i_{t+1}\right)}{\partial \phi_{t+1}}\right]} \\
& <(1-\tau) \frac{\partial \phi_{t+1}}{\partial \tau} w^{s}\left[(1-\alpha)(1-\tau)\left[\left(1+i_{t+1}\right)-\frac{\partial\left(1+i_{t+1}\right)}{\partial \phi_{t+1}} \phi_{t+1}\right]\right]
\end{aligned}
$$

with $\frac{\partial\left(1+i_{t+1}\right)}{\partial \phi_{t+1}}<0$, and $h\left(1+i_{t+1}\right)-w^{s} \phi_{t+1},(1-\alpha)(1-\tau)\left(1+i_{t+1}\right)-1>0$.

(ii) The minimum level of wealth necessary to invest in skills declines in response to an increase in taxes, since

$$
\begin{aligned}
\frac{\partial x_{t}^{c r i t}}{\partial \tau}= & {\left[-w^{u}(1+\bar{r})+h \frac{\partial(1+i)}{\partial \phi_{t}} \frac{\partial \phi_{t}}{\partial \tau}-\frac{\partial \phi_{t}}{\partial \tau}\left(w^{s}-w^{u}\right)\right] } \\
& -\frac{1}{i-\bar{r}}\left[(1-\tau) w^{u}(1+\bar{r})+h(1+i)-\phi_{t}\left(w^{s}-w^{u}\right)\right]<0,
\end{aligned}
$$

since the first term in squared brackets is negative while the second term in squared brackets equals $x_{t}^{\text {crit }}$ which is positive.

According to item (i) of Proposition 6, the change of $x_{*, \phi_{t+1}}^{u, s}$ in response to an increase in $\tau$ is ambiguous: Because of (33), an improvement in life expectancy financed by an increase in $\tau$ has an ambiguous effect on $x_{*, \phi_{t}}^{u, s}$ through the decline in $i_{t+1}$. On the one hand, it increases second period income $w^{s} \phi_{t}-h(1+i)$ (reduces debts), but diminishes the return on wealth. If condition (50) is met, the latter effect is lower than the former. Item (ii), in turn, states that $x_{t}^{\text {crit }}$ is negatively associated to an increase in taxes. Both results in combination affect the dynamics of the wealth distribution. Given a favorable distribution of wealth, $\Gamma_{t}$, it is possible that the reduction in $x_{t}^{c r i t}$ and $x_{*, \phi_{t+1}}^{u, s}$ affects all unskilled households, such that the longrun composition of households exhibits only skilled dynasties. Then, the induced asymmetric impact of $\tau$ on the exterior steady states doesn't play any role. The 
adverse impact on the inferior steady state gains in importance, however, the larger the initial amount of inequality is. Furthermore, we can not exclude the case that a decline in $x_{t}^{c r i t}$ is accompanied by an increase in $x_{*, \phi_{t+1}}^{u, s}$, such that in an extreme case dynasties would start to invest in skills initially, but their descendants would cease to acquire human capital since the basin of attraction of the inferior steady state is at least temporarily larger.

We now turn our attention to the effects of a change in the public expenditure share for health care services, $\nu$, given $\tau$ on the (conditional) steady states and on $x_{t}^{\text {crit }}$.

Proposition 7 (Effects of $\nu$ on $x_{*, \phi_{t+1}}^{s}$ and $x_{*, \phi_{t+1}}^{u}$ ) The steady states of the skilled and the unskilled population group increase in response to an increase in $\nu$

$$
\begin{aligned}
\frac{\partial x_{*, \phi_{t+1}}^{s}}{\partial \nu} & =\frac{(1-\tau)(1-\alpha) w^{s}}{1-(1-\tau)(1+\bar{r})(1-\alpha)} \frac{\partial \phi}{\partial \nu}>0 \\
\frac{\partial x_{*, \phi_{t+1}}^{u}}{\partial \nu} & =\frac{(1-\tau)(1-\alpha) w^{u}}{1-(1-\tau)(1+\bar{r})(1-\alpha)} \frac{\partial \phi}{\partial \nu}>0
\end{aligned}
$$

such that $\frac{\partial x_{*, \phi_{t+1}}^{s}}{\partial \nu}>\frac{\partial x_{*, \phi_{t+1}}^{u}}{\partial \nu}$ since $w^{s}>w^{u}$ and given $\phi_{t+1}<1$.

In light of the last proposition it becomes apparent that an increasing health expenditure share benefits both population groups while an increase in $\tau$ could benefit the skilled but harm the unskilled. Nevertheless, the skilled population group again benefits more in terms of long-run wealth, such that even this policy change increases inequality in the long-run. But again, the long-run distribution of the population over the two exterior steady states is influenced by the dynamics of the conditional interior steady state, $x_{*, \phi_{t+1}}^{u, s}$, and $x_{t}^{c r i t}$. The reaction of $x_{*, \phi_{t+1}}^{u, s}$ and $x_{t}^{\text {crit }}$ is summarized in the following proposition. ${ }^{8}$

Proposition 8 (Effects of $\nu$ on $x_{*, \phi_{t+1}}^{u, s}$ and $x_{t}^{c r i t}$ ) (i) The interior steady state declines in response to an increase in $\nu$, if

$$
\begin{aligned}
& w^{s}-h \frac{\partial\left(1+i_{t+1}\right)}{\partial \phi_{t+1}}<(1-\alpha)(1-\tau)\left(\left(1+i_{t+1}\right)-\frac{\partial\left(1+i_{t+1}\right)}{\partial \phi_{t+1}} \phi_{t+1}\right) w^{s} \\
& \text { since } \frac{\partial\left(1+i_{t+1}\right)}{\partial \phi_{t+1}}<0 \text { and } \frac{\partial \phi_{t+1}}{\partial \nu} \geq 0 .{ }^{9}
\end{aligned}
$$

(ii) The minimum level of wealth necessary to invest in skills declines in response to an increase in taxes, as

$$
\begin{aligned}
\frac{\partial x_{t}^{c r i t}}{\partial \nu} & =\left[h \frac{\partial\left(1+i_{t+1}\right)}{\partial \phi_{t+1}} \frac{\partial \phi_{t+1}}{\partial \nu}-\frac{\partial \phi_{t+1}}{\partial \nu}\left(w^{s}-w^{u}\right)\right] \\
& -\frac{1}{i_{t+1}-\bar{r}}\left[(1-\tau) w^{u}(1+\bar{r})+h\left(1+i_{t+1}\right)-\phi_{t+1}\left(w^{s}-w^{u}\right)\right]<((5,4)
\end{aligned}
$$

since the first term in squared brackets is negative while the second term in squared brackets equals $x_{t}^{\text {crit }}$ which is positive.

\footnotetext{
${ }^{8}$ The qualitative results are similar to Proposition 6.

${ }^{9}$ See the explanation following Proposition 6.
} 


\section{$5 \quad$ Numerical Experiments}

In this section, we explore the dynamics of our economy numerically. The set of parameters is presented in Table 1. The capital income share, $\gamma$, is set to 0.3. Since one period encompasses approximately 30 years, we set the rate of capital depreciation, $\delta$, equal to $1 . \bar{r}=4$ implies an annual interest rate of $4.7 \%$. The weight of consumption in the utility function, $\alpha$, is 0.85 . The parameter $\beta=1.6$ implies a borrowers' interest rate of $9 \%$ p.a., if $\phi_{t}=1$. As far as the evolution of the pollution stock is concerned, there are obviously several degrees of freedom. We therefore fix $\eta=0.95$ which seems to be plausible over 30 years. The remaining parameters are fixed in combination with the survival function, $\phi_{t}$, (see Eq. (55)) in an iterative way assuring that life expectancy starts around 0.5 and the transition to the steady state is completed after 8 periods, i.e. 240 years.

Table 1: Parameters

\begin{tabular}{|c|c|}
\hline Technology & $\gamma=0.3 ; \delta=1 ; a=0.2 ; \mathrm{b}=8$ \\
\hline Pollution & $\eta=0.95 ; \varepsilon_{0}=0.1 ; \varepsilon_{1}=0.048 ;$ \\
\hline Human capital & $\beta=1.6 ; h=0.515 ; \bar{r}=4$ \\
\hline Preferences & $\alpha=0.85$ \\
\hline$\Phi=\{\tau, \nu\}$ & $\tau=0.1 ; \nu=0.8$ \\
\hline
\end{tabular}

We assume that life expectancy follows a logistic function in health expenditures and pollution

$$
\phi_{t}=\frac{F+A * 0.0001}{0.0001+\exp \left(-k *\left(\psi_{H} H_{t}-\psi_{P} P_{t}\right)\right) *(A / F-1)},
$$

with $F=0.5 ; k=10 ; A=200 ; \psi_{H}=0.0038 ; \psi_{P}=0.0005$.

In performing the numerical experiments, we generate an artificial sample of households $(N=1000)$ and draw the initial level of wealth $x_{0}^{j}, j \in N$ out of a log-normal distribution $\mathcal{F}_{0} \sim\left(\mu_{x} ; \sigma_{x}\right)$. Since our experiments will deal with different amounts of initial inequality, we increase the variance of initial wealth, but keep the mean of the distribution constant and assure therefore the comparability between the experiments.

Our first experiment deals with different amounts of initial inequality in terms of wealth. The evolution of the wealth distribution over time is depicted in Figure 5: the left-hand panel shows the kernel density estimation for the first periods for different amounts of initial inequality and the right-hand panel depicts the overall transition of the wealth distribution. Since the population converges either to $x_{*, \phi_{*}}^{s}$ or $x_{*, \phi_{*}}^{u}$, the wealth distribution collapses into two spikes located at $x_{*, \phi_{*}}^{u}$ and $x_{*, \phi_{*}}^{s}$, with the height of the two spikes representing the amount of inequality.

In Figure 6, we present the dynamics of the conditional steady states $x_{*, \phi_{t+1}}^{u}, x_{*, \phi_{t+1}}^{u, s}$, $x_{*, \phi_{t+1}}^{s}$ towards their respective stationary values indicated by subscript $\phi_{*}$, and the critical level of wealth necessary to invest in skills, $x_{t}^{\text {crit }}$. The baseline scenario with 

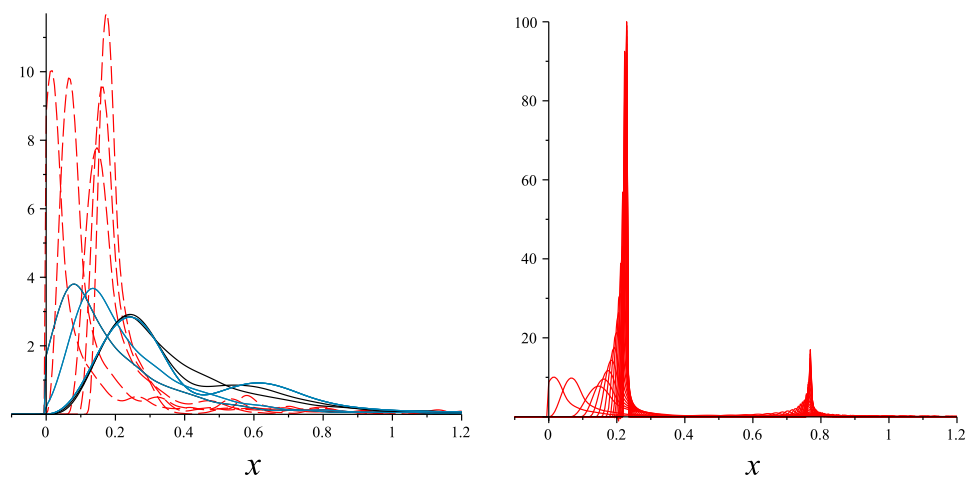

Figure 5: Evolution of the wealth distribution (kernel density estimation) - left-hand panel: first five periods (dashed: increased inequality (mean preserving spread); solid: baseline scenario) - right-hand panel: complete transition of the baseline scenario

low initial inequality is depicted in solid lines and the scenario characterized by higher initial inequality is illustrated by dashed lines. As regards the response of the conditional steady states and $x_{t}^{\text {crit }}$ to improvements in life expectancy, Figure 6 reflects the insights of Figure 4. Figure 7 shows the dynamics of aggregate output, $Y$, tax revenues, $G$, pollution, $P$, life expectancy, $\phi$, the number of skilled and unskilled households, $n^{j}, j=s, u$, and the number of unskilled households investing in skills, $n^{u, s}$. The baseline scenario is again depicted in solid lines while dashed lines represent the scenario characterized by higher initial inequality.

During the initial stages of economic development, production is low which implies low levels of pollution. Tax revenues are low as well allowing only for low levels of public health care expenditures and hence low levels of life expectancy. There are no incentives to invest in skills, since a low value of the life expectancy, $\phi$, implies high interest rates of borrowers and a short amortization period of human capital investment. These dynamics are reflected by the fact that the conditional steady state of the unskilled, $x_{*, \phi_{t}}^{u}$, exceeds the conditional steady state that results from skill investments, i.e. $x_{*, \phi_{t}}^{s}$ (see Figure 6). Therefore, the entire population is composed of unskilled households, i.e. $n^{u}=N$. Since wealth evolves according to (28), the tax base of the government will however increase over time allowing for an increase in health expenditures and consequently an increase in life expectancy. Although the increase in life expectancy is ineffective with respect to human capital investment, as long as $\phi<\phi^{c}$, it is effective insofar as an increase in $\phi$ increases labor supply, and therefore the level of aggregate production. Moreover, higher life expectancy increases the second period income of unskilled households, i.e. lifetime earnings and therefore the accumulation of wealth. Both factors in combination increase tax revenues and life expectancy even further. In the simulation with low inequality, the threshold level of $\phi=\phi^{c}$ is reached in period $t=5$. From period five onwards, the conditional steady state of unskilled households falls below the conditional steady 


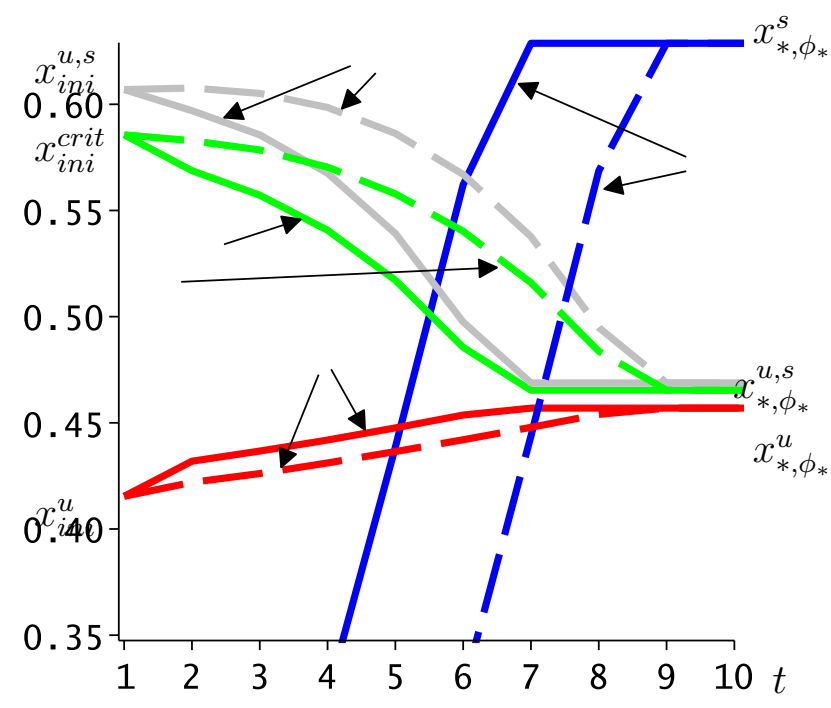

Figure 6: Dynamics of the conditional steady states and $x_{t}^{\text {crit }}$ with different amounts of initial inequality. High inequality $=$ dashed lines; low inequality $=$ solid lines.

state of skilled households $\left(x_{*, \phi_{t+1}}^{u}<x_{*, \phi_{t+1}}^{s}\right)$, inducing households with $x_{t}^{j}>x_{t}^{c r i t}$ to invest in skills. Since further increases in $\phi$ reduce borrowers' interest rate $i_{t+1}$, and thereby $x_{t}^{c r i t}$ and $x_{*, \phi_{t}}^{u, s}$, more and more unskilled households are not only willing to invest in skills but are also attracted by the superior steady state in the long-run. ${ }^{10}$ The endogenous switch to human capital accumulation increases the level of output since a more productive technology is used. As we assume a symmetric impact of the skilled and the unskilled sector on the environment, the pollution stock increases as a consequence of an increased level of aggregate production. ${ }^{11}$

An increase in initial inequality has no impact on the long-run values of wealth per household $x_{* \phi_{*}}^{u}, x_{*, \phi_{*}}^{u, s}$ and $x_{*, \phi_{*}}^{s}$ given that $\phi_{*}=1 .{ }^{12}$ Nevertheless a higher amount of initial inequality reduces the tax base since agents accumulate wealth at a slower pace. Consequently, life expectancy rises more slowly as compared to the lowinequality scenario. Accordingly, since lifetime earnings are lower, the levels of the

\footnotetext{
${ }^{10}$ Remember the reduction in $x_{t}^{c r i t}$ and $x_{*, \phi_{t}}^{u, s}$ reduces the basin of attraction of the inferior steady state.

${ }^{11}$ Note that the model is also able to account for an Environmental Kusnetz Curve, if we would assume an asymmetric impact of both sectors on the environment in the sense that the $s$-sector would harm the environment less as compared to the $u$-sector. In this case, the evolution of the pollution stock would read as $P_{t+1}=(1-\eta) P_{t}+\varepsilon_{0}^{u} Y_{t}^{u}+\varepsilon^{s} Y_{t}^{s}-\varepsilon_{1} A_{t}$ with $\varepsilon_{0}^{u}>\varepsilon_{0}^{s}$.

${ }^{12}$ Off course an extreme case of initial inequality could result in a long-run value of $\phi_{*}$ below 1 such that the long-run values of $x$ would be reduced as well.
} 

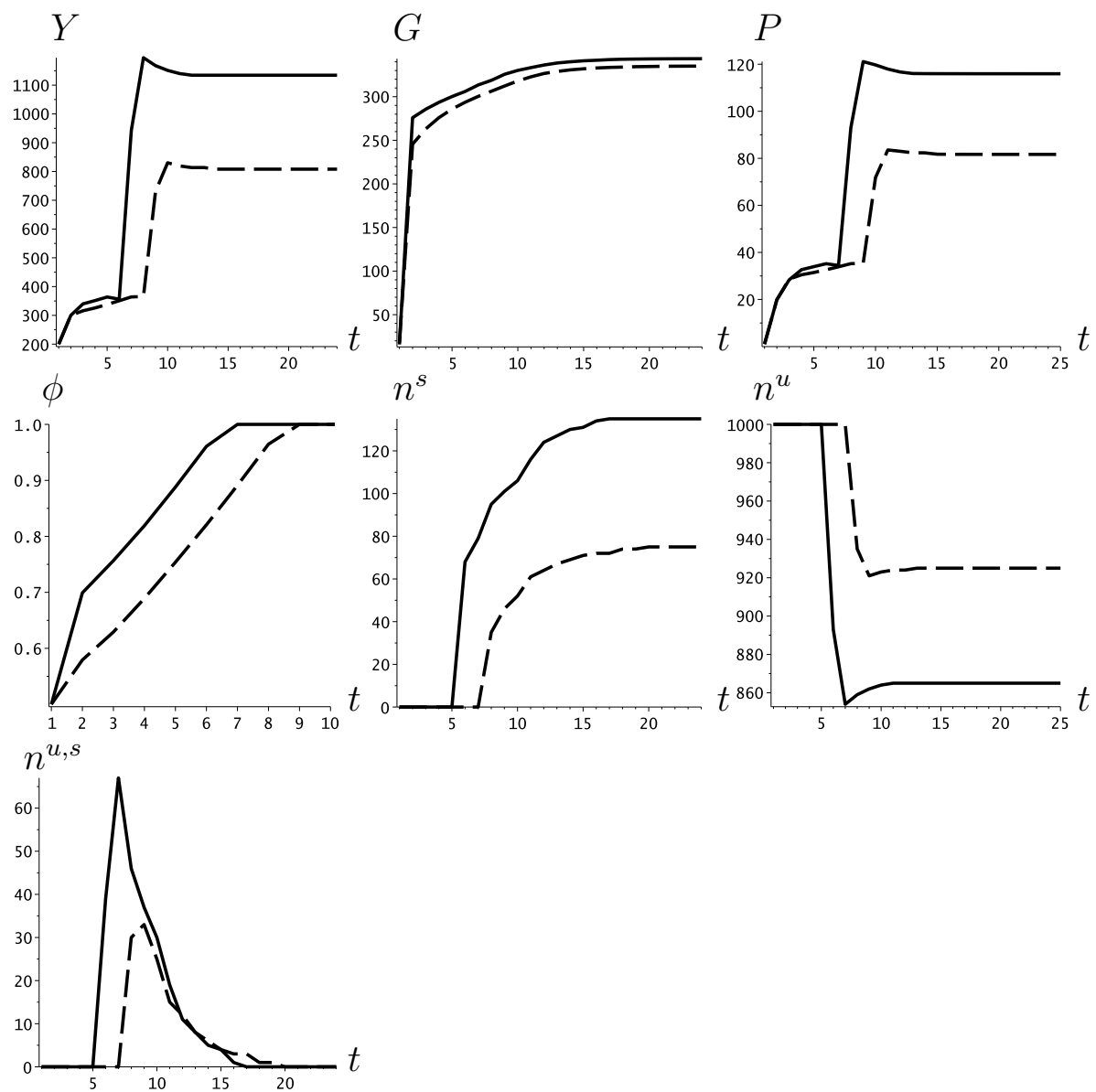

Figure 7: Dynamics of aggregate Output, $Y$, tax revenues, $G$, pollution stock, $P$, life expectancy, $\phi$, the number of skilled and unskilled households $n^{j}, j=u, s$ and the number of unskilled households investing in skills, $n^{u, s}$, with different amounts of initial inequality. High inequality $=$ dashed lines; low inequality $=$ solid lines.

conditional exterior steady states are reduced as well (see Figure 6). Consequently, the threshold level $\phi^{c}$ is only reached in period $t=7$ and the take-off in terms of human capital accumulation is delayed by two periods. Since the transition of life expectancy is delayed due to a higher initial inequality, the levels of $x_{* \phi_{t+1}}^{u, s}$ and $x_{t}^{c r i t}$ are also higher during the transition. ${ }^{13}$ The latter has far reaching consequences for the long-run performance of the economy. Although the conditional steady states and $x_{t}^{\text {crit }}$ as well as the the level of life expectancy converge to the same long-run values, the transitory higher value of $x_{t}^{\text {crit }}$ hinders more unskilled households to invest in human capital while more unskilled households that invested in human capital are still in the basin of attraction of the inferior steady state caused by the increase in $x_{*, \phi_{t+1}}^{u, s}$. Therefore, the economy exhibits a lower number of skilled households as compared to the low-inequality scenario. Summing up, a larger amount of initial

\footnotetext{
${ }^{13}$ This effect stems from lower life expectancies and higher interest rates.
} 

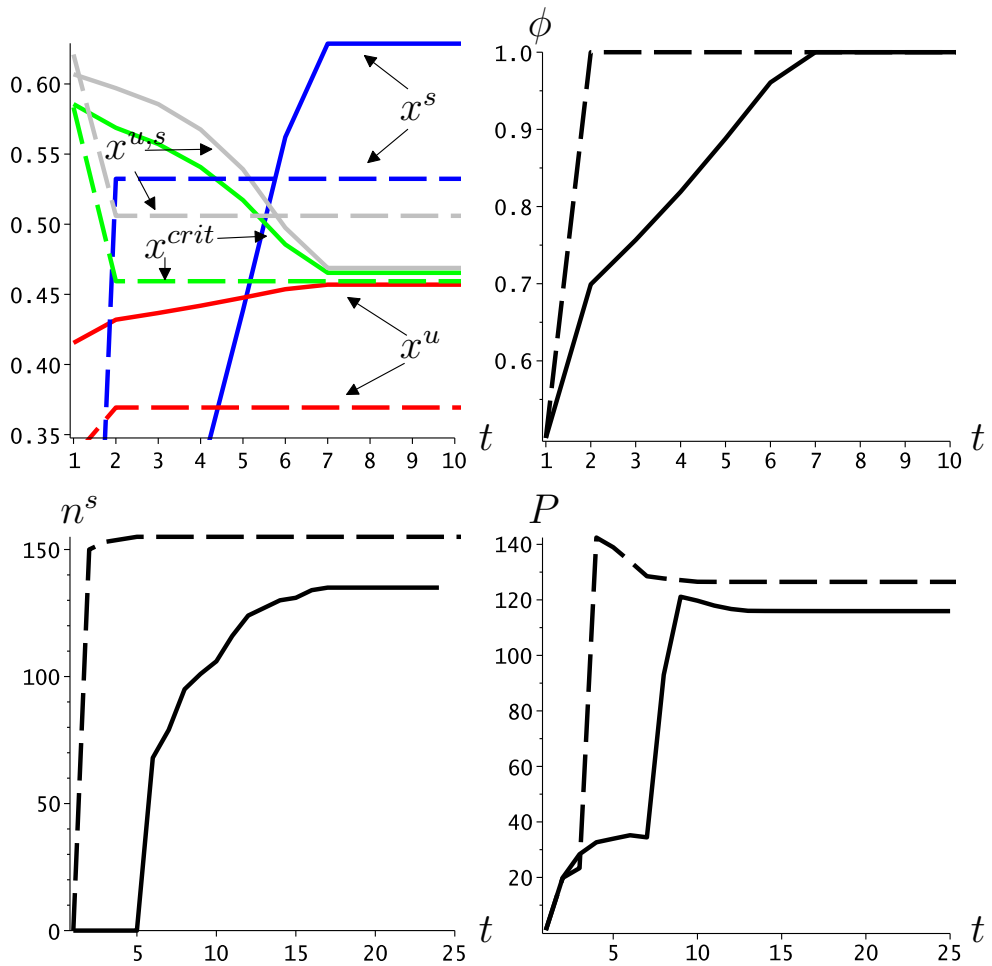

Figure 8: Dynamics of the conditional steady states, $x_{t}^{\text {crit }}$, life expectancy, $\phi$, the pollution stock, $P$, and the number of skilled households, $n^{s}$, with different tax rates $(\tau=0.15$ : dashed lines; $\tau=0.1$ : solid lines).

inequality reduces the tax base and therefore the effectiveness of the policy set on life expectancy $\phi$, for any exogenously fixed level of $\Phi$ and initial level of pollution. The lower production level (due to less skilled workers) reduces the pollution level.

Having explored the effects of different degrees of initial inequality on the longrun performance of the economy, as reflected by the level of aggregate output and pollution, we turn our focus now to changes in in the policy set $\Phi$. We start with a change in the income tax rate $\tau$ and compare the results (as presented in Figure 8) to the baseline scenario. Thereafter, we analyze the impact of higher initial inequality in the high-tax regime with the low-tax regime (see Figure 9). Finally, we conduct the same experiments with different shares of public health care, i.e. $\nu$.

In Figure 8, the high-tax scenario is depicted by dashed lines while the low-tax scenario is presented by solid lines. Higher taxes increase expenditures for public health care and abatement measures. Therefore life expectancy $\phi$ increases faster as compared to the reference scenario. Accordingly the critical level of life expectancy, $\phi^{c}$, is reached already in period $t=2$. From now on the conditional steady state that applies for households that wish to acquire human capital is above the conditional steady state of the unskilled population group. During the transition, the conditional steady states of the high-tax regime are above the ones of the low-tax regime. This 
fact is owed to the fast increase in life expectancy which compensates households for the lower post-tax income at a given level of life expectancy. In later stages of economic development, the effect of reduced post-tax incomes overcompensates further gains in life expectancy such that the long-run levels of wealth for both population groups are reduced compared to the reference scenario with lower taxes. Unskilled households with a relatively high level of inherited wealth may benefit from a faster increase in life expectancy inasmuch as the critical level of wealth necessary to acquire skills and the interior conditional steady state not only declines faster but converges also to a lower long-run steady state. Thus the basin of attraction of the superior exterior steady state extends. Accordingly, the favorable evolution of life expectancy increases the number of skilled households, thereby aggregate production and pollution compared to the reference scenario.

Nevertheless it is worth to notice that there may be a draw back of a higher tax rate depending on the initial distribution of wealth. As we have shown, the favorable evolution of life expectancy induces a fast decline in $x_{t}^{c r i t}$ and $x_{*, \phi_{t+1}}^{u, s}$. This increases human capital investments and enhances the possibility of households with a level of wealth below $h$ to transit in the long-run towards the superior steady state. However, this possibility depends on the initial amount of inequality. Given a more unfavorable initial distribution of wealth, the fast decline in $x_{t}^{u, s}$ may block the transition of unskilled households that acquired human capital towards the superior equilibrium, such that the number of skilled households shrinks. This effect is shown in Figure 9. There, we consider two regimes that are characterized by high initial inequality but different tax rates. The high-tax regime is again depicted in dashed lines while the low-tax regime is presented in solid lines. Apparently, higher inequality reduces the favorable impact of higher taxes on human capital investments, but reduces the level of pollution.

In our next experiment we analyze a change in the expenditure share for public health care, $\nu$, see Figure 10. Contrary to a change in $\tau$, a change in $\nu$ leaves (c.p.) disposable incomes of households unaffected. The long-run values of wealth for different population groups remain unaffected given that $\phi_{*}=1$. Like an increase in $\tau$, an increase in $\nu$ induces a faster increase in life expectancy which favors human capital investments. ${ }^{14}$ Since, the long-run values of wealth are unaffected by a change in $\nu$, and the number of skilled households has increased, the economy's tax base will increase compared to the base line scenario. That is, although economic activity and its adverse impact on the environment have increased, there are also more resources available for abatement measures due to an increase in the tax base. Therefore, the level of pollution is similar compared to the one resulting from an increase in taxes although the number of skilled households and hence the level of economic activity has increased even further (compare Fig. 10 and Fig. 8).

\footnotetext{
${ }^{14}$ Like in Figure 8, the increase in $\nu$ induces also a fast decline in $x_{t}^{c r i t}$ and $x_{\phi_{t}, *}^{u, s}$ such that the benefit of an increased $\nu$ depends also in this case on the initial distribution of wealth.
} 

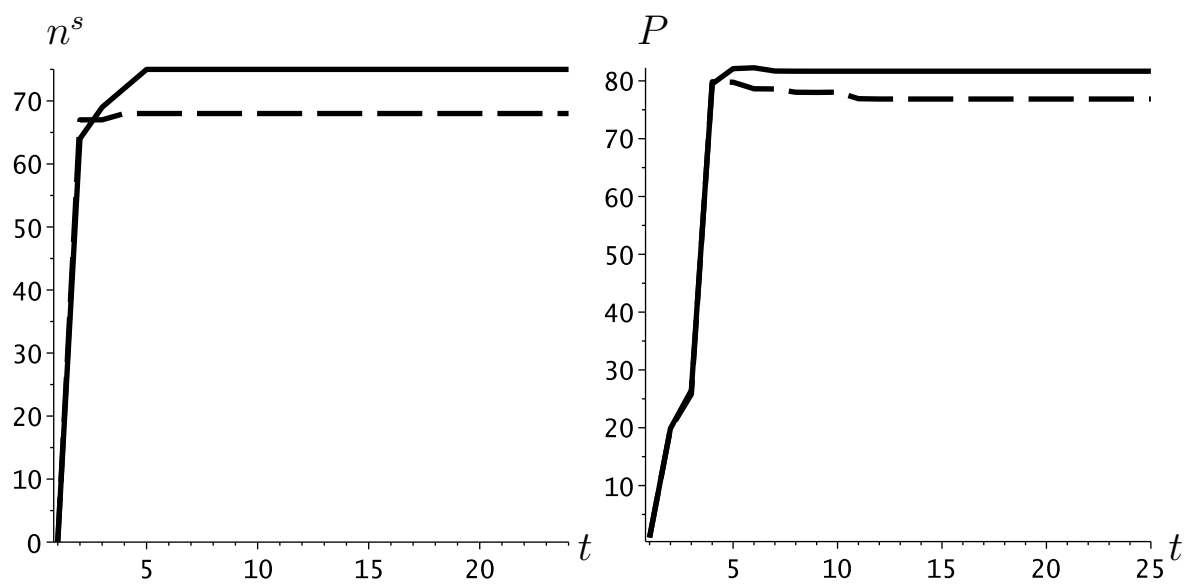

Figure 9: Dynamics of the number of skilled households, $n^{s}$, and the pollution stock, $P$ with different tax rates $(\tau=0.15$ : dashed lines; $\tau=0.1$ : solid lines) and higher initial inequality.

\section{Discussion}

By only focusing on public health care we aim to emphasize the role of the allocation of public expenditures between health care and pollution abatement on economic growth (see also Agenor and Neanidis 2011). On one hand health expenditures reduce income through taxes thereby also reducing spending on pollution abatement, on the other hand higher taxes allow for an increase in health expenditures thereby inducing a higher life expectancy and fostering human capital accumulation and economic growth.

Our analysis is valid for a given policy set, $\Phi$, but we refrain from modeling explicitly the political process which may explain this policy set. That is, we analyze for a given policy set, the interplay between economic inequality, human capital investment and life expectancy while the latter is, in turn, influenced by the specific policy set, $\Phi$, while the effectiveness of $\Phi$ depends on the amount of inequality. Nevertheless our framework opens an avenue for future research which takes account for the endogenous determination of $\Phi$. Obviously, the determination of $\Phi$ requires a two-stage optimization with respect to $\nu$ and $\tau$.

Assume that the government sets the tax rate given an optimal division of expenditures between health and abatement policy, $\nu$. Then the government would seek to maximize the utility of a representative agent, $j$, for example the median voter, which could be either a skilled agent, an unskilled agent or a descendant of an unskilled household that invests in skills. Thus, the government would maximize 

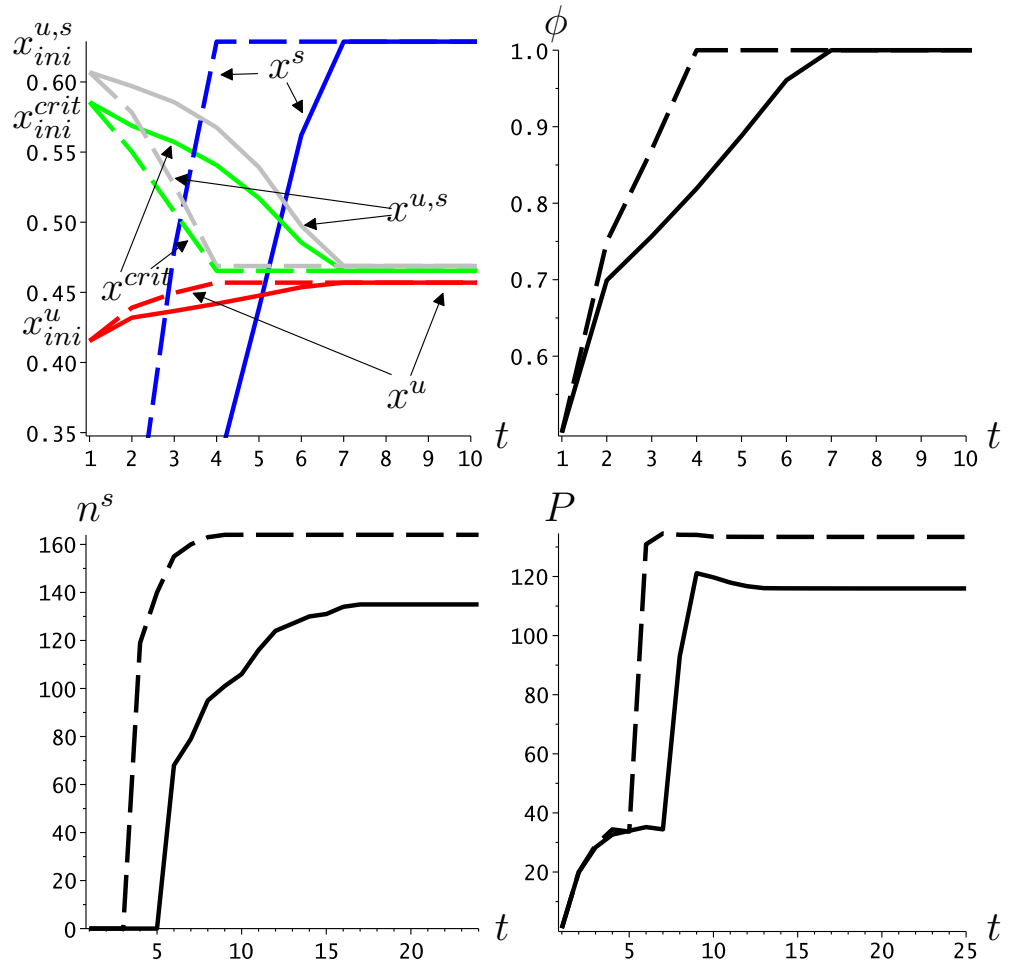

Figure 10: Dynamics of the conditional steady states, $x_{t}^{\text {crit }}$, life expectancy, $\phi$, the pollution stock, $P$, and the number of skilled households, with different expenditures shares $\nu$ for public health cares $(\nu=0.85$ : dashed lines; $\nu=0.8$ : solid lines).

agent $j$ 's lifetime utility (15)

$$
\max _{0 \leq \tau \leq 1}\left\{\phi_{t}\left[\bar{\alpha}+\ln \left[(1-\tau) y_{t}^{j}\right]\right]\right\}
$$

The associated first-order condition reads

$$
\frac{\partial \phi_{t}}{\partial \tau}\left[\bar{\alpha}+\ln \left[(1-\tau) y_{t}^{j}\right]\right]+\frac{\phi_{t}}{(1-\tau) y_{t}^{j}}\left[-y_{t}^{j}+(1-\tau) \frac{\partial y_{t}^{j}}{\partial \phi_{t}} \frac{\partial \phi_{t}}{\partial \tau}\right]=0
$$

The term $-y_{t}^{j}$ in large squared brackets on the left hand side captures the marginal cost of taxes while the first term on the left hand side and $(1-\tau) \frac{\partial y_{t}^{j}}{\partial \phi_{t}} \frac{\partial \phi_{t}}{\partial \tau}$ capture the marginal benefit of an increase in taxes due to the associated increase in the survival probability. Obviously, the marginal benefit of raising taxes is zero, if $\phi_{t}=1$ and/or $\frac{\partial \phi_{t}}{\partial \tau}=0$, such that the first-order condition reduces to $-\frac{\phi_{t}}{(1-\tau)} \cdot{ }^{15}$ As has been discussed already, an income tax is welfare improving as long as the benefits that result from an increase in life expectancy and the associated increase in lifetime earnings over compensate the income loss. Thus, the preferred tax rate depends on the sensitivity (curvature) of the survival function in response to changes in $P$ and

\footnotetext{
${ }^{15}$ Note that $\phi_{t}=1$ implies $\frac{\partial \phi_{t}}{\partial \tau}=0$ but $\frac{\partial \phi_{t}}{\partial \tau}=0$ may also result for $\phi_{t}<1$.
} 
$H$ and the income level of the representative agent. In addition it seems reasonable that wealthier agents are less exposed to pollutants as compared to poorer agents. Thus the marginal benefit of wealthier agents may be lower which explains that the new entrepreneurial class saw no point in paying taxes for sanitation in cities. We come back to this point further below in this section.

As the life expectancy, $\phi_{t}$, is increasing in aggregate health expenditures $H_{t}$, the welfare maximizing expenditure share would be $\nu=1$. This result can be explained by the fact that the current pollution stock can not be reduced by current abatement measures, $A_{t}=(1-\nu) G_{t}$, and that the generation born in $t-1$ behaves entirely selfish in the sense that their impact on the future pollution stock is not internalized by their lifetime utility function. Thus non-altruistic agents would opt for zero abatement measures. This result would change, if we assume at least imperfect altruism with respect to the future stock of pollution. An illustrative example may be represented by the following utility function:

$$
u_{t}^{j}=\phi_{t}\left[\bar{\alpha}+\ln \left[(1-\tau) y_{t}^{j}\right]\right]-\pi \ln \left[P_{t+1}\right]
$$

where $\pi$ reflects the weight of environmental damages for the future generation captured by the pollution stock in the subsequent period. The first-order condition thus reads

$$
\frac{\partial \phi_{t}}{\partial \nu}\left[\bar{\alpha}+\ln \left[(1-\tau) y_{t}^{j}\right]\right]+\frac{\phi_{t}}{(1-\tau) y_{t}^{j}}\left[(1-\tau) \frac{\partial y_{t}^{j}}{\partial \nu} \frac{\partial \phi_{t}}{\partial \nu}\right]-\frac{\pi}{P_{t+1}} \frac{\partial P_{t+1}}{\partial \nu}=0 .
$$

In light of the last expression it becomes apparent that although $\phi_{t}$ is an increasing function in $\nu$ it is not necessarily welfare maximizing to set $\nu=1$ given that the marginal benefit from abatement weighted by $\pi$ is sufficiently high.

As we just clarified, we may expect that the marginal benefit of taxation for wealthier agents is low or even zero, a phenomenon which is very much in line with historical observations. The significance of water as an industrial raw material has been documented by Hassan (1985): fresh water was used for commercial purposes while the new entrepreneurial class saw no point in spending money for sanitation and sewage treatment plants. This finding points directly at the role of economic inequality especially as wealthier households moved to cleaner areas with significantly lower exposures to local pollutants. In this line of argumentation Szreter (1997) stresses

... there is indeed something intrinsically dangerous and socially destabilizing in the wake of economic growth... .

He underlines his statement by the following two observations: (1) local authorities ere failing the management of their environments, and, as regards the role of inequality, (2) as a consequence of it wealthier citizens moved to the periphery of the cities.

Our setting does not include spatial segregation and differential exposures to pollutants. Nevertheless it opens an avenue to analyze the emerging social conflict 
between wealthier citizens living in cleaner areas and the majority of people living in overcrowded and polluted cities. This can be achieved by regionally differing survival functions capturing the local impact of pollutants on citizen's survival probability (see Schaefer 2013).

\section{Summary and Conclusions}

Based on the work by Galor and Zeira (1993), we analyzed the link between economic inequality in terms of wealth, life expectancy and pollution. The distribution of wealth is decisive for the number of households investing in human capital. Moreover, the willingness to invest in human capital is affected by agents' life expectancy since it triggers the length of the amortization period of human capital investments. In our framework, life expectancy is endogenous and positively affected by public health care expenditures but adversely affected by the pollution stock stemming from aggregate production.

Due to a low level of health expenditures owed to a low level of tax revenues, life expectancies are low in earlier stages of economic development such that there is no incentive to invest in human capital. Nevertheless, increasing accumulation of wealth increases step by step the tax base and agents' life expectancy. After a threshold level of life expectancy has been passed, households begin to acquire skills. Our model is therefore able to take account for an endogenous taker-off in terms of human capital accumulation.

Higher initial inequality retards the take-off, since the tax base of the economy is reduced which implies lower expenditures on public health care and abatement measures. Consequently, the increase in life expectancy is slower. The latter in turn reduces human capital investments, such that the economy is characterized by a lower aggregate long-run level of production and pollution. In other words, higher inequality reduces the effectiveness of a given set of economic policies in terms of health and abatement expenditures.

An increase in taxes or the expenditure share for public health care increases life expectancy. The more favorable evolution of the life expectancy is beneficial for human capital investment given that the initial distribution of wealth is not too unequal. An increase in taxes, given a higher amount of initial inequality, may be harmful in the sense that less descendants of unskilled households invest in skills. In general, an increase in taxes reduces long-run wealth of households. Contrary to an increase in taxes, an increase in the public health expenditure share leaves (c.p.) disposable incomes of agents constant, such that the long-run levels of wealth per household remain unaffected or even increase. Since the more favorable evolution of life expectancy increases the tax base, higher health care expenditure shares increase in general (like an increase in the tax rate) the number of skilled households and the level of aggregate production in the long-run. The advantage compared to an increase in taxes however is the achieved increase in the tax base which induces more expenditures on health care and abatement measures, such that an even higher 
economic activity is compatible with a similar level of long-run pollution. 


\section{References}

Agenor, P.R., K.C. Neanidis, 2011. The Allocation of Public Expenditure and Economic Growth. The Manchester School 79: 899-931.

Aisa, R., F. Pueyo, 2006. Government health spending and growth in a model of endogenous longevity. Economics Letters 90: 249-253.

Chay, K.Y, M. Greenstone, 2003. The impact of air pollution on infant mortality: Evidence from geographic variation in pollution shocks induced by a recession. Quarterly Journal of Economics, August: 1121-1167.

Galor, O., J. Zeira, 1993. Income distribution and macroeconomics. Review of Economic Studies 60: 35-52.

Haines, M.R., 2004. Growing incomes, shrinking people - can economic development be hazardous to your health? Social Science History 28: 249-270.

John, A., R. Pecchenino, 1994. An overlapping generations model of growth and the environment. The Economic Journal 104: 1393-1410.

John, A., R. Pecchenino, D. Schimmelpfennig, S. Schreft, 1995. Short-lived agents and the long-lived environment. Journal of Public Economics 58(1): 127-141.

Komlos, J., 1998. Shrinking in a growing economy? The mystery of physical stature during industrial revolution. Journal of Economic History 58: 779-802.

Mariani, F, A. Perez-Barahona, N. Raffin, 2010. Life expectancy and the environment. Journal Economic Dynamics and Control 34: 798-815.

Raffin, N., T. Seegmuller, 2012. Longevity, Pollution and Growth. EconomiX Working Paper, No. 2012-47.

Schaefer, A., 2013. The Growth Drag of Pollution. University of Leipzig Working Paper.

Szreter, S., 1997. Economic growth, disruption, disease and death: on the importance of the politics of public health for development. Population and Development Review, 23: 693-728.

Worldbank 2007, http://www.worldbank.org/en/news/press-release/2007/07/11/statementworld-bank-china-country-director-cost-pollution-china-report. 


\section{Mathematical Appendix}

Proof of Proposition 4

We first show that $x_{\phi_{t}, *}^{u, s}$ is hump-shaped. In the second step, we demonstrate that $x_{t}^{c r i t}$ is hump-shaped as well and always below $x_{\phi_{t}, *}^{u, s}$.

(1) Since $\lim _{\phi_{t} \rightarrow 0} x_{\phi_{t}, *}=h$ and $x_{\phi_{t}, *}^{s}=x_{\phi_{t, *}}^{u, s}=h$, if $\phi_{t}=\phi^{c}=\frac{h}{(1-\alpha)(1-\tau) w^{s}}$ it follows that $x_{\phi_{t}, *}^{u, s}$ is non-monotonous is $\phi_{t}$. As moreover

$$
\lim _{\phi_{t} \rightarrow 0} \frac{\partial x_{\phi_{t, *}^{u, s}}^{u, s}}{\partial \phi_{t}}=\frac{(\beta-1) h}{\beta(1-\alpha)(1-\tau)(1+\bar{r})}>0,
$$

it follows outright that $x_{\phi_{t}, *}^{u, s}$ is hump-shaped.

(2) Since $\lim _{\phi_{t} \rightarrow 0} x_{t}^{c r i t}=h$ and

$$
\lim _{\phi_{t} \rightarrow 0} \frac{\partial x_{t}^{c r i t}}{\partial \phi_{t}}=\frac{\beta-1}{\beta}\left((1-\tau) w^{u}+h\right)>0
$$

it follows that $x_{t}^{c r i t}=x_{\phi_{t}, *}^{u, s}=h$ as $\phi_{t}$ approaches zero and that $x_{t}^{c r i t}$ has a initially a positive slope as well. Moreover, $x_{t}^{\text {crit }}$ has a unique intercept with $x_{\phi_{t, *}}^{u, s}$ and $x_{\phi_{t}, *}^{u}$, such that $x_{t}^{c r i t}=x_{\phi_{t, *}}^{u, s}=x_{\phi_{t, *}}^{u}$, if $\phi_{t}=\tilde{\phi}$. Since $x_{\phi_{t, *}}^{u, s}$ cuts $x_{\phi_{t, *}}^{s}$ from above at $\phi^{c}$ while $x_{\phi_{t}, *}^{u}$ is strictly below $x_{\phi_{t, *}}^{s}$ for $\phi_{t}>\phi^{c}$, it follows that $\tilde{\phi}>\phi^{c}$. Since the intercept between $x_{t}^{c r i t}$ and $x_{\phi_{t}, *}^{u, s}$ is unique it follows that $x_{t}^{\text {crit }}$ is hump-shaped in $\phi_{t}$ as well and always below $x_{\phi_{t}, *}^{u, s}$ for $\phi_{t}<\tilde{\phi}$.

(3) From (1) and (2) it follows immediately that $x_{t}^{c r i t}$ and $x_{\phi_{t}, *}^{u, s}$ are declining in $\phi_{t}$ for $\phi^{c} \leq \phi_{t} \leq \phi_{*}$. 